Canadian Journal of Fisheries and Aquatic Sciences

Canadian Science Publishing

Journal canadien des sciences halieutiques et aquatiques

\title{
Understanding inter-reach variation in brown trout (Salmo trutta) mortality rates using a hierarchical Bayesian state- space model
}

\begin{tabular}{|r|l|}
\hline Journal: & Canadian Journal of Fisheries and Aquatic Sciences \\
\hline Manuscript ID & cjfas-2016-0240.R2 \\
\hline Manuscript Type: & Article \\
\hline Date Submitted by the Author: & 07-Jan-2017 \\
\hline Complete List of Authors: & $\begin{array}{l}\text { BRET, Victor; EDF R\&D, LNHE } \\
\text { CAPRA, Hervé; IRSTEA, MALY } \\
\text { GOURAUD, Véronique; EDF R\&D, LNHE } \\
\text { LAMOUROUX, Nicolas; IRSTEA, MALY } \\
\text { Piffady, Jérémy; IRSTEA, MALY } \\
\text { Tissot, Laurence; EDF R\&D, LNHE } \\
\text { Rivot, Etienne; Agrocampus Ouest, INRA, UMR 985 ESE Ecology and } \\
\text { Ecosystem Health }\end{array}$ \\
\hline Keyword: & $\begin{array}{l}\text { Brown trout, POPULATION DYNAMICS < General, Density-dependence, } \\
\text { spatial variation, Hierarchical Bayesien model }\end{array}$ \\
\hline \multicolumn{2}{|l}{} \\
\hline
\end{tabular}

\section{SCHOLARONE \\ Manuscripts}




\section{Understanding inter-reach variation in brown trout (Salmo trutta) mortality}

2 rates using a hierarchical Bayesian state-space model

3 Victor Bret ${ }^{1}$, Hervé Capra ${ }^{2}$, Véronique Gouraud ${ }^{1, *}$, Nicolas Lamouroux $^{2}$, Jérémy Piffady ${ }^{2}$, Laurence

4 Tissot $^{1}$, Etienne Rivot ${ }^{3}$

$5 \quad{ }^{1}$ EDF R\&D, LNHE Department, HYNES (Irstea - EDF R\&D), 6 Quai Watier, Chatou Cedex 78401, 6 France

$7 \quad 2$ IRSTEA Lyon, UR MALY, HYNES (Irstea - EDF R\&D), 5 Rue de la Doua, BP 32108, 69616

8 Villeurbanne Cedex, France

$9 \quad{ }^{3}$ UMR 985 ESE Ecology and Ecosystem Health, Agrocampus Ouest, INRA, 35042 Rennes, France

$10 *$ Corresponding author

11 


\section{Abstract}

13 Successful management and protection of wild animal populations relies on good understanding of 14 their life-cycles. Because population dynamics depends on intricate interactions of biological and 15 ecological processes at various scales, new approaches are needed that account for the variability of demographic processes and associated parameters in a hierarchy of spatial scales. A hierarchical

17 Bayesian model for the resident brown trout (Salmo trutta) life cycle was built to assess the relative 18 influence of local and general determinants of mortality. The model was fitted to an extensive data set 19 collected in 40 river reaches, combining abundance and environmental data (hydraulics, water temperature). Density-dependent mortality of juveniles increased at low water temperatures and decreased with shelter availability. High water temperature increased density-dependent mortality in adults. The model could help to predict monthly juvenile and adult mortality under scenarios of global warming and changes in shelter availability due to habitat degradation or restoration.

\section{Keywords}

25 Hierarchical Bayesien model, Brown trout, population dynamics, mortality, density-dependence, spatial variation 


\section{Introduction}

Population Dynamics Models (PDM) can capture the intricate demographic and ecological mechanisms that control the course of a population's life cycle. They contribute to decision-making for the management of fisheries (e.g., Rochette et al. 2013), invasive species (e.g., Dauer et al. 2012) or the prediction of climate change impacts (e.g., Petitgas et al. 2013). PDMs built on large scales, using data from multiple distant sites, are attractive for assessing the impact of large-scale processes such as climate patterns (e.g., Joly et al. 2011) on populations. However, local variations in population dynamics (e.g., in mortality or reproductive success; Coulson et al. 1999; Brickhill et al. 2015) can reduce the explanatory and predictive power of large-scale models that ignore variability of processes among populations. Local variations in population dynamics also threaten the transferability of PDMs calibrated locally: i.e., using extensive knowledge from monitoring one or few sites (e.g., Buenau et al. 2014). Therefore, there is a need to develop new approaches in population dynamics modeling, taking account of variability in demographic processes in a hierarchy of spatial scales to capture both patterns of variation shared by all populations and local variations, and to investigate the influence of environmental factors and anthropic pressure in a hierarchy of scales.

Hierarchical Bayesian Models (HBM) of population dynamics are useful tools to account for variability among populations (e.g., Li and Jiao 2015) due to processes operating at various scales (e.g., Ebersole et al. 2009). Moreover, HBMs can account for multiple sources of stochasticity in processes and observations, and can provide inferences on all unknowns in a full probabilistic framework (Harwood and Stokes 2003; Lek 2007; Buckland et al. 2004; Parent and Rivot 2013; Newman et al. 2014). Thus, HBMs have been widely used to model a wide range of populations (e.g., tree dynamics; McMahon et al. 2009), including age-structured (e.g., Simmonds et al. 2010; Rochette et al. 2013) or stage-structured (Swain et al. 2009) marine fish populations. However, fewer studies have used HBMs to model freshwater population dynamics (e.g., Rivot et al. 2004; Borsuk et al. 2006; Letcher et al. 2015; Kanno et al. 2016). 
Brown trout (Salmo trutta) is one of the most widely studied freshwater fish species (Klemetsen et al. 2003) and its life-cycle has been well described (Elliott 1994; Klemetsen et al. 2003; Gouraud et al. 2014). Brown trout is typically found in headwaters, many of which have been regulated for uses such as drinking water supply and hydropower generation. Therefore, efficient management decisions require data from extensive (and expensive) long-term monitoring within a variety of headwater streams and models to predict the impact of regulations on brown trout population.

Studies explicitly comparing brown trout population dynamics among several sites are rare, but reveal considerable spatial variation. For instance, Lobón-Cerviá et al. (2012) identified differences in mortality patterns between a Spanish and a Danish population. Spatial variations were also identified among close populations (e.g., variations in competition strength and survival within a watershed; Fernandez-Chacon et al. 2015). A major source of inconsistency among studies of brown trout population dynamics lies in the identification of density-dependent mortality. This process was described theoretically a long time ago (Ricker 1954; Beverton and Holt 1957) and has been identified for all age-stages of the brown trout life cycle (Elliott 1994; Elliott and Hurley 1998; Nicola et al. 2008). However, many studies failed to detect density-dependent mortality, especially for young agestages (Elliott and Hurley 1998; Lobón-Cerviá 2014). Such differences among studies suggest considerable spatial variation in mortality. A second source of inconsistency is due to the methods used to model environmental effects on fry mortality. Strong flow during the first months of life has frequently been related to high mortality (Hayes 1995; Cattanéo et al. 2002; Gouraud et al. 2008; Lobón-Cerviá 2014; Tissot et al. 2016), but the environmental variables used to model the process varied among studies. For instance, discharge thresholds (e.g., maximum mean daily flood) have often been used, although they correspond to very different hydraulic constraints in different rivers. Describing high flow based on standardized quantitative variables for the hydraulic habitat of brown trout (e.g., depth, velocity) might reduce these inconsistencies.

In this paper, a HBM is built to analyze resident brown trout population dynamics. The model is based on a complete representation of their life cycle, and is designed to analyze inter-reach variation in mortality to better understand the role of density-dependence. Five age-stages were distinguished, and 
80

81

82

both density-independent and density-dependent mortality were included in the model. The model was fitted on an extensive data set collected in 40 river reaches, combining brown trout data with detailed physical habitat characteristics (e.g., hydraulics, water temperature). The reaches had a wide range of physical characteristics; half of them were below dams that diverted part of the flow. Degree of variation in mortality among reaches was quantified, and its relation with the physical characteristics of reaches was tested.

\section{Materials \& methods}

The model was designed to capture the population dynamics of brown trout in 40 reaches of 23 rivers distributed across continental France (Fig. 1). Each reach included one or several sequences of pools, runs and/or riffles. Reaches had a wide range of physical characteristics (Table 1). They mainly comprised upstream sections of mountain streams with cold water, although three were in coastal plain streams (in Brittany and Normandy). A total of 19 reaches were below dams that diverted part of the flow (Fig. 1). These reaches had reduced low flows (defined by the national legislation on minimum flows) and reduced flood frequencies compared to an unregulated situation.

The model was constructed in a state-space form that included both process errors in dynamics and observation errors in data (Rivot et al. 2004; Buckland et al. 2004; Newman et al. 2014). We describe below the life-cycle model (section 2.1), the dataset used to fit the HBM and the associated observation (likelihood) equations (2.2), leave-one-out deletion tests and comparison of model fits with and without density-dependence (2.3).

\subsection{The life-cycle model}

The life-cycle model was based on eight demographic processes, summarized below (2.1.1) and further detailed in Appendix A (e.g., stage duration, equations).

\subsubsection{Demographic transitions}

The stage-structure PDM distinguished five age-stages (Fig. 2): under-gravel development (Egg), emergence (E), end of first year (0), second year (1) and adult stage (Ad). The dynamics of brown 
trout density for a given age-stage $k\left(D_{k}\right.$, ind $\left./ 100 \mathrm{~m}^{2}\right)$ was modeled using 1 -month time steps considering different processes. The model considered eight successive processes: (p1) spawning, (p2) under-gravel egg mortality, (p3) flow-velocity related mortality during emergence, mortality during: (p4) emergence, (p5) end of first year (after emergence), (p6) second year of life (juvenile), and (p7) the following years (Fig. 3). Adult mortality until spawning (p8) was also included, to predict adult density at spawning, $D_{A d, S p w}$.

The spawning process (p1) was described assuming that the initial egg density $D_{E g g}$ could be related to $D_{A d, S p w}$, sex-ratio $\varphi$, number of eggs per $\mathrm{kg}$ of females $\psi$ and weight (in $\mathrm{kg}$ ) of adult brown trout $K g_{A d}$.

Fry mortality during emergence (p3) has been reported when flow velocity was too high (e.g., Heggenes and Traaen 1988; Armstrong et al. 2003). The influence of flow velocity was therefore modeled as an excess-mortality rate $\mu$, operating when $V_{10, E}$ (daily flow velocity exceeded more than $10 \%$ of the time during emergence) was higher than a threshold $Z$ (in $\mathrm{m}_{\mathrm{s}} \mathrm{s}^{-1}$ ). This potential abiotic mortality was added to the density-dependent mortality considered in $\mathrm{p} 4$.

The 6 mortality processes (p2; p4-p8) were modeled using 1-month time steps following a BevertonHolt (1957) relationship (Quinn and Deriso 1999). This model considers both density-independent and density-dependent instantaneous mortality ( $\delta_{k}$ and $\gamma_{k}$ respectively), assumed to be constant during the whole age-stage $k$. The strength of both processes could therefore be studied separately. A $\gamma_{k}$ value close to 0 indicates low density-dependence for mortality. As the model assumes a closed system and therefore fails to distinguish mortality from emigration, $\delta_{k}$ and $\gamma_{k}$ were apparent mortality rates, including both mortality as such and emigration. Instantaneous mortality rates are integrated over the duration of age-stage $k, \Delta m_{k}$ to provide the classical Beverton-Holt density-dependent relationship between density at stage $k$ and stage $k+1$ :

(Eq.1)

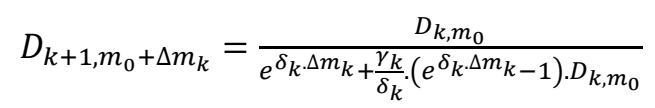


129

130

131

132

133

134

Eq. 1 can also be used to express intermediate densities within an age-stage if $\Delta m<\Delta m_{k}$. This was used to model density at month of sampling $\left(D_{k_{S p l}}\right)$ or month of spawning.

Process errors took account of unpredictable among-year variations around the expected process (Eq. 1). They were described as log-normal error, defined by its log-scale standard deviation, $\sigma_{k}$ (estimated but considered constant among reaches and years).

\subsubsection{Hierarchical structure and fixed parameters}

\subsubsection{Parameters fixed from the literature}

As we did not have local data on spawning processes and egg mortality in our reaches, parameters related to these processes ( $\mathrm{p} 1$ and $\mathrm{p} 2$ ) could not be estimated and were fixed at values from the literature. We used previous studies on French brown trout populations to obtain estimates for sexratio $\varphi$, number of eggs per $\mathrm{kg}$ of females $\psi$, and instantaneous mortality rates during the undergravel development stage $\delta_{\text {Egg }}$ and $\gamma_{\text {Egg }}$ (Table 2). These 4 parameters were considered constant over reaches and years. In particular, it was assumed that no density-dependent mortality occurred during egg incubation (thus fixing $\gamma_{\mathrm{Egg}}=0$ ).

\subsubsection{Parameters estimated and considered constant among reaches and years}

All other parameters were estimated by the model from our data and were given weakly informative prior distributions (Table 3).

It was assumed that abiotic mortality (p3) could be modeled similarly in the various reaches, as a function of flow velocity. Thus, $\mu$ and $Z$ (excess-mortality rate and velocity threshold, respectively) were assumed to be constant among sites and years. Inter-year variation in emergence mortality $(\mathrm{p} 4)$ is known to be high and mostly related to abiotic conditions (Hayes et al. 2010; Lobón-Cerviá et al. 2012). Thus, inter-reach variation was assumed to be negligible, and the parameters $\delta_{\mathrm{E}}$ and $\gamma_{\mathrm{E}}$ were considered constant among reaches.

As the remaining age-stages $(0,1$ and $A d)$ were sampled, data were available to study inter-reach variation in their mortality rates. An initial version of the model (online supplementary material) considered inter-reach variation in all mortality rates: it revealed limited inter-reach variation in 
mortality at the end of the first year $\left(\delta_{0}\right.$ and $\left.\gamma_{0}\right)$ and in density-independent mortality during the second year of life $\left(\delta_{1}\right)$. Thus, to keep the model more parsimonious, these 3 parameters were modeled as constant over reaches and years.

\subsubsection{Parameters estimated and considered as varying among reaches}

The initial version of the model indicated large inter-reach variation in mortality during the adult agestage $\left(\delta_{\mathrm{Ad}}\right.$ and $\left.\gamma_{\mathrm{Ad}}\right)$ and in density-dependent mortality during the second year of life $\left(\gamma_{1}\right)$ (online supplementary material). These 3 parameters were therefore modeled using a hierarchical setting:

$\theta_{r} \sim \operatorname{LogN}\left(E_{\theta}, \sigma_{\theta}\right)$

(with $\theta=\delta_{\mathrm{Ad}}, \gamma_{1}$ or $\gamma_{\mathrm{Ad}}$ )

enabling shared processes to be identified (expected value $E_{\theta}$ for parameter $\theta$ for all reaches $r$ ) while integrating reach specificities (represented by the dispersion parameter $\sigma_{\theta}$ ).

\subsubsection{Explaining inter-reach variation by reach characteristics}

\subsubsection{Integration of covariates in the hierarchical setting}

The hypothesis that inter-reach variation in $\delta_{\mathrm{Ad}}, \gamma_{\mathrm{Ad}}$ and $\gamma_{1}$ could be explained by reach characteristics was further explored, focusing on 6 reach characteristics that might influence mortality: shelter availability, low and high water temperature, reach width, hydraulic suitability of habitat, and intensity of natural regime alteration (Table 4; data detailed in section 2.2.2). The fully exchangeable model in Eq. 2 was then extended to a partially exchangeable model (Rivot and Prévost 2002; Parent and Rivot 2013) in which the expected mean $E_{\theta, r}$ of a mortality rate $\theta$ in reach $r$ was modelled as a linear combination of the above 6 reach characteristics:

$$
E_{\theta, r}=\sum_{c=1}^{6} \beta_{c, \theta} * X_{c, r}+\alpha_{\theta}
$$

with $X_{c, r}$ the characteristic $c$ of reach $r$ (measured data), $\alpha_{\theta}$ the intercept, and $\beta_{c, \theta}$ the slope related to characteristic $c$.

\subsubsection{Identification of influential covariates}

The Stochastic Search Variable Selection (SSVS) method (George and McCulloch 1993) was used to identify the most influential environmental covariates in Eq. 3. SSVS is one of several methods 
180

181

182

183

184

185

186

187

developed for variable selection in Bayesian frameworks (O'Hara and Sillanpaa 2009) and has proved effective in linking fish ecology to environmental covariates (Piffady et al. 2013). The principle is to introduce latent covariates in Eq. 3, enabling variable selection to be embedded in a Markov Chain Monte Carlo (MCMC) sampling process. Eq. 3 is then extended by using auxiliary variables $I_{c, \theta}$ that indicate the presence $\left(I_{c, \theta}=1\right)$ or absence $\left(I_{c, \theta}=0\right)$ of covariate $c$ for parameter $\theta$ within the model. All coefficients $\beta_{c, \theta}$ in Eq. 3 were then given a mixture prior distribution known as 'spike and slab' (George and McCulloch 1993):

$$
P\left(\beta_{c, \theta} \mid I_{c, \theta}\right)=\left(1-I_{c, \theta}\right) B 0_{c, \theta}+I_{c, \theta} B 1_{c, \theta}
$$

The idea is to give $\beta_{c, \theta}$ a very informative prior distribution centered on 0 when $I_{c, \theta}=0$ (through $B 0_{c, \theta}$ ), thus "turning off" the influence of this covariate. When $I_{c, \theta}=1$, then $\beta_{c, \theta}$ is given a less informative prior distribution $\left(B 1_{c, \theta}\right)$, likely to be updated if this covariate has an influence. Priors distributions $B 1_{c, \theta}$ and $B 0_{c, \theta}$ are set as Normal distributions with 0 mean and standard deviations $\tau$ and $g \tau$ respectively ( $g$ having a high positive value) (Table 3). As parameters $\tau$ and $g$ needed to be tuned, we used $\tau=0.05$ and $g=500$. A sensitivity analysis to test various values of $\tau$ and $g$ (combinations of $\tau$ from 0.01 to 0.1 and $g$ from 100 to 1,000) revealed no effect of changing those values, and will not be detailed further. Values taken by $I_{c, \theta}$ were drawn in a Bernoulli distribution with prior probability of $50 \%$ (a-priori equiprobablity of presence or absence). The posterior frequency of inclusion (i.e., number of iterations in the model with $I_{c, \theta}=1$ ) indicated whether factor $c$ was likely to explain variations in the expected mean of mortality rate $\theta$. When only low posterior frequencies of inclusion $(<50 \%)$ were estimated for a given mortality rate, this indicated that the investigated reach characteristics did not explain inter-reach variation.

\subsection{Data and observation equations}

The PDM was fitted to annual density estimates for the various life-stages (determined by electrofishing) and to environmental variables available for the 40 reaches in the 23 rivers (Fig. 1). 


\subsubsection{Brown trout density estimates}

\subsubsection{Electrofishing data}

Between 4 and 20 surveys (i.e., reach $\times$ year combinations; mean: 10.7) were conducted per reach between 1990 and 2013. Reaches were sampled by wading, using two-pass removal electrofishing sampling, meeting European Committee for Standardization guidelines (CEN 2003). At every reach $r$ and every year $y$, observed brown trout densities $\left(D_{O_{o b s}, r, y}, D_{1_{o b s}, r, y}\right.$ and $\left.D_{A d_{o b s}, r, y}\right)$ were estimated with the Carle and Strub (1978) method.

Brown trout sampling was performed without upstream or downstream blocking nets, in summer or early fall (median date: September 10). The total sampled area (between 175 and 2,902 $\mathrm{m}^{2}$ ) was computed as sampled length $\times$ reach width at median flow. Due to changes in sampling teams or harsh hydraulic conditions during some surveys, sampled length was slightly modified (variation $>5 \%$ in measured sampled length) in 13 reaches during the study period. Such changes concerned $9 \%$ of the surveys (maximum length change: $25 \%$; median change: $9 \%$ ). The length of one reach was halved in the middle of the time series, but still considered a single reach for analysis as its hydraulic characteristics remained unchanged.

All fish were measured (total length, to the nearest $1 \mathrm{~mm}$ ), and length-frequency histograms distinguished 3 age-groups: 0+ (young-of-the-year), 1+ (between 1 and 2 years old) and adult (all fish older than two years). To confirm the suitability of using length-frequency distributions, scales were analyzed (see Sabaton et al. 2008) for 10 reaches. Adults were considered as the potential reproductive pool. Adult fish were also weighed to measure $\mathrm{Kg}_{50, r}$, the inter-annual median of observed weights in reach $r$.

\subsubsection{Observation equations}

Sampling data $\left(D_{O_{O b s}, r, y}, D_{1_{O b s}, r, y}\right.$ and $\left.D_{A d_{o b s}, r, y}\right)$ were observations of intermediate states of the lifecycle, occurring during processes p5, p6 and p7 respectively (Fig. 2; Fig. 3). The model predicted density at time of sampling $\left(D_{S_{S p l}, r, y}, D_{1_{S p l}, r, y}\right.$ and $\left.D_{A d_{S p l}, r, y}\right)$, as the 1-month time-step allowed among-year variation in sampling date to be integrated. Process errors took account of unpredictable 
230

231

232

233

234

235

236

237

238

239

240

241

242

243

244

245

246

247

248

249

250

251

252

253

254

255

among-year variation around the expected process (Eq. 1). Observation errors took account of uncertainty around the Carle-Strub procedure. Raw capture data were first used to calculate the relative standard deviation around the estimated density, noted as $R S D_{k, y}$ (Zippin formula; Gerdeaux 1987). Density estimates and associated uncertainty were then used as pseudo-observations in the pseudo-likelihood method (Michielsens et al. 2008). To avoid negative values, a log-normal distribution was assumed for observed densities $D_{k_{O b s}, r, y}$ around $D_{k_{S p l}, r, y}$ with a standard deviation in log-scale expressed by $R S D_{k, y}$.

When raw capture data were not available (11\% of samples), measurement error was estimated using the $75^{\text {th }}$ percentile of all $R S D$ s.

\subsubsection{Environmental data}

Daily hydraulic conditions and water temperature were determined for all reaches and each year preceding fish sampling, using methods detailed by Bret et al. (2015). Daily water temperature was measured in 21 reaches ( $43 \%$ of the sampling period covered on average) and predictive models were used to estimate missing values. Reach-averaged hydraulic conditions (e.g., flow velocity or wetted width) were derived from daily discharge data and from numerical hydraulic models or detailed hydraulic measurements made throughout each reach at several discharge rates. Annual values of $V_{10 \mathrm{E}, \mathrm{r}, \mathrm{y}}$ were calculated based on these data.

To test the hypothesis that inter-reach variation in mortality could be explained by reach characteristics, 6 characteristics (Table 4), obtained by field measurement in each reach $r$, were selected and standardized before being introduced in the model. Shelter availability $\left(\right.$ Shelt $\left._{r}\right)$ was described as the ratio of sheltered area (under a rock or the bank) to total wetted area. The mean of annual percentiles of water temperatures $\left(T_{10, r}\right.$ and $\left.T_{90, r}\right)$ was used to summarize the extreme range of thermal regimes. The mean of annual median wetted widths $\left(L_{50, r}\right)$ was used to describe stream size. Habitat suitability was described by the Habitat Suitability Index at median discharge $\left(H S I_{50, r}\right)$, calculated using the instream habitat models of Lamouroux and Capra (2002) (28 reaches), Sabaton and Miquel (1993) (5 reaches) or Ginot et al. (1998) (7 reaches) depending on available data. The 
strength of natural regime alteration was represented by the height of the nearest upstream dam

$257\left(\right.$ ham $\left._{r}\right)$

258

259

260

261

262

263

264

265

266

267

268

269

270

271

272

273

274

275

276

\subsubsection{MCMC simulations}

Posterior distributions were inferred via MCMC sampling using JAGS software (information at http://mcmc-jags.sourceforge.net) and the R package R2jags (Plummer et al. 2015). Three independent MCMC chains were run, starting at different random initial values. After a "burn-in" period of 80,000 iterations, $3 \times 40,000$ iterations were sampled, 1 in 10 being recorded to reduce sampling autocorrelation. The Gelman-Rubin diagnostic (Brooks and Gelman 1998) was used to test for chain convergence (Gelman-Rubin statistics $<1.1)$.

\subsection{Model stability and comparison with a model without density-dependence}

Leave-one-out deletion tests were used to estimate the reliability of the SSVS and sensitivity of parameter estimates to small changes in data. The model was fitted on 40 different subsets of 39 reaches (leaving out 1 reach in turn per subset). Posterior frequencies for inclusion of reach characteristics were compared to assess SSVS stability. Posterior means of all parameters' posterior distributions were also compared to evaluate the stability of parameter estimates.

Finally, to assess the consequences of integrating density-dependence, the model including the environmental variables selected by the SSVS procedure was compared to a model with all densitydependent mortality rates set to 0 (only density independent mortality). The explanatory power of the two models was compared, based on their log-scaled Root Mean Square Error (RMSE) computed as

$\sqrt{\frac{1}{n} \sum_{i=1}^{n}\left(\log \left(D_{S p l, k, i}\right)-\log \left(D_{O b s, k, i}\right)\right)^{2}}$ for each of the three sampled age-stages $k$, where $D_{S p l, k, i}$ is the fitted density and $D_{O b s, k, i}$ is the pseudo-observation. 


\section{Results}

278

279

280

281

282

283

284

\subsection{Explaining mortality variation by reach characteristics}

Inter-reach variation was found for density-independent mortality for the adult age-stage $\delta_{\mathrm{Ad}}$ and density-dependent mortality for the $1+$ and adult age-stages $\left(\gamma_{1}\right.$ and $\gamma_{A d}$; see online supplementary material). The SSVS revealed that, of the 6 reach-specific characteristics, only shelter availability and water temperature explained these inter-reach variations (Fig. 4A). There was an influence of reach shelter availability (Shelt) on density-dependent mortality for the $1+$ age-stage $\left(\gamma_{1}\right)$ (posterior frequency of inclusion $=85 \%$; Fig. 4A), describing decreasing density-dependence with shelter availability (mean value of posterior PDF of $\beta_{\text {Shelt }, \gamma_{1}}=-1.2$; Table 5; Fig. 5, second row). Densitydependent mortality for the $1+$ age-stage $\left(\gamma_{1}\right)$ was also increased by low water temperatures $\left(T_{90}\right.$; posterior frequency of inclusion $=70 \%$; Fig. 4A; Table 5; Fig. 5, third row). There was finally an influence of high water temperatures $\left(T_{10}\right)$ on density-dependent mortality for the adult age-stage $\left(\gamma_{A d}\right)$ (posterior frequency of inclusion $=74 \%$; Fig. 4A), describing increasing density-dependence with high water temperature (mean value of posterior PDF of $\beta_{T_{10}, \gamma_{A d}}=0.3$; Table 5; Fig. 5, fourth row). No reach characteristics significantly explained the variations in adult density-independent mortality $\left(\delta_{A d} ;\right.$ Fig. 5, first row).

These results were confirmed by the leave-one-out deletion tests (Fig. 4B). The posterior frequency of inclusion of Shelt (influencing $\gamma_{1}$ ), $T_{90}$ (influencing $\gamma_{1}$ ) or $T_{10}$ (influencing $\gamma_{A d}$ ) remained $>50 \%$ in respectively $100 \%, 92.5 \%$ and $97.5 \%$ of the cases. The influence of high water temperature on adult density-dependent mortality appeared strong (Fig. 5, fourth row) when considering all reaches. However, one deletion test (removal of the Clarée reach) showed surprising results for adults: interreach variation in $\gamma_{A d}$ was explained by shelter availability (posterior frequency of inclusion when removing the Clarée reach $=71 \%$ ) rather than by high water temperatures (posterior frequency of inclusion of $\left.T_{10}=35 \%\right)$. This reach exhibited low shelter availability (Shelt Clarée $\left.=0.6 \%\right)$, low water temperatures $\left(T_{10, \text { Claré }}=12^{\circ} \mathrm{C}\right)$ and low density-dependent mortality for the adult $\left(\gamma_{\text {Ad,claré }}=0.003\right)$ and induced a bias in our results. Other variables that were removed from the model (influence of 
reach width, habitat suitability or natural regime alteration on $\delta_{A d}, \gamma_{1}, \gamma_{A d}$ and of thermal regime and shelter availability on $\left.\delta_{A d}\right)$ always showed the lowest probability of inclusion $(<42 \%)$.

\subsection{Variations in mortality according to age-stage}

Monthly mortality differed widely among age-stages (Table 5). The lowest were $\delta_{0}, \delta_{1}, \gamma_{0}$ (posterior means always $<0.001$ ) and $\gamma_{1, r}$ (posterior means $<0.002$ for 24 reaches; max: 0.038) (Fig. 6). Other monthly mortality rates were much higher. The highest mortality occurred during emergence (posterior mean of $\left.\delta_{E}=0.24, \gamma_{E}=0.02\right)$. Estimates of $\delta_{E}$ revealed a wide uncertainty $(50 \%$ of the posterior PDF within $[0.12 ; 0.33])$. The posterior means of the 40 fitted $\delta_{A d, r} \mathrm{~s}$ ranged between 0.003 and 0.160 (mean: 0.014 ) and posterior means of the $\gamma_{A d, r} \mathrm{~s}$ ranged between 0.002 and 0.026 (mean: $0.010)$.

The posterior distributions of parameters showing high flow influence on recruitment ( $\mu$ and $Z$; Table 5) revealed very high mortality in emerging fry ( $94 \%$; posterior mean of $\mu$ ) for flow velocity $\left(V_{10 \mathrm{E}, \mathrm{r}, \mathrm{y}}\right)$ $>1.15 \mathrm{~m} . \mathrm{s}^{-1}$ (posterior mean of $Z$ ). Extreme mortality was therefore modeled for only $8 \%$ of studied years. Combined with the high density-dependent mortality during emergence $\gamma_{E}$, this produced estimates of $0+$ density very stable among reaches (see Fig. 7, right panel), associated with high process error.

\subsection{Comparing observed and predicted density}

The model was indeed able to predict temporal change in 1+ and adult density (see Fig. 7 for an example of 2 reaches), but often overlooked $0+$ temporal density variation. This was quantified by the posterior mean of the RMSE for these age groups (1.23.1, 0.72 and 0.50 for $0+, 1+$ and adults respectively). The high values of posterior PDF for $\sigma_{0}, \sigma_{1}, \sigma_{A d}$ revealed a considerable influence of process error: real density in $50 \%$ of samplings was within a range of $\left[0.5^{*} \mathrm{D}_{0_{\mathrm{Spl}}}-2.0^{*} \mathrm{D}_{0_{\mathrm{Spl}}}\right]$ for $0+$, $\left[0.6 * \mathrm{D}_{1_{\mathrm{Spl}}}-1.5 * \mathrm{D}_{1_{\mathrm{Spl}}}\right]$ for $1+$ and $\left[0.8 * \mathrm{D}_{\mathrm{Ad}} \mathrm{Spl}-1.3 * \mathrm{D}_{A d_{\mathrm{Spl}}}\right]$ for adults. 


\subsection{Stability of the model and comparison with a model without density-dependence}

Results of the leave-one-out deletion test showed that inferences were fairly robust with respect to moderate changes within data sets. The relative standard deviations on the study parameters were always $<10 \%$. RMSE was also very stable ( $<2.5 \%$ variation) for all age-stages, showing that the quality of fit of the model to the data was not dependent on any data in particular.

By contrast, a priori setting all density-dependent parameters to 0 and estimating density-independent mortality only decreased the explanatory power of the model, as log-scale RMSE values were higher (1.40, 0.82 and 0.54 for $0+, 1+$ and adults, corresponding to respective increases of $14 \%, 14 \%$ and $8 \%$ ), showing that density-dependence was important in explaining the data.

\section{Discussion}

\subsection{Fitting the brown trout life-cycle}

The extensive dataset analyzed in this study enabled construction of a hierarchical Bayesian statespace model for the life-cycle of resident brown trout. While previous attempts to model brown trout life-cycle used no or few data (e.g., Van Winkle et al. 1998; Daufresne and Renault 2006) or adopted a deterministic approach with literature-based parameters (e.g., Railsback et al. 2009; Tissot et al. 2016), our population dynamics model is merged within a statistical approach in which most state variables and parameters were estimated from field data, accounting for both process and observation errors (Rivot et al. 2004; Buckland et al. 2007; Parent and Rivot 2013).

Posterior distributions of mortality estimated on our 40 reaches were consistent with values reported in the literature. High mortality during emergence (p4) has long been reported (e.g., between $85 \%$ and 98\% of mortality occurred during emergence for the 4 years studied by Elliott 1994). The present pattern of low mortality during age-stages 0 and 1 (p5 and p6) was also identified by samplings made every 2 months on two Spanish reaches for 11 and 14 years by Lobón-Cerviá (2012). Mean annual adult mortality at mean adult density (53\%; Fig. 6 p7) was consistent with previous reports (50\%; Baglinière and Maisse 1991), but ranged between $20 \%$ at low density and $80 \%$ at high density. 
351

352

353

354

355

356

357

358

359

360

361

362

363

364

365

366

367

368

369

370

371

372

373

374

375

376

377

Results, based on long term monitoring of 40 reaches, confirmed that density-dependence is a major feature of brown trout population dynamics. Indeed, integrating density-dependent mortality $(\gamma)$ into natural mortality processes (p2; p4-p8) improved the explanatory power of the model. Wide variations were identified in the strength of density-dependence among reaches (Fig. 6): annual mortality of juveniles (p6) and adults (p7) could vary 2-fold for a given initial density of $1+$ or adults, only due to variations in $\gamma$.

\subsection{Inter-reach variation in mortality}

Results revealed a high variability of survival across reaches. Contrasting reaches distributed across France and exhibiting a wide range of physical characteristics (Table 2) were included in the analysis. While some mortality rates were very stable across all reaches $\left(\delta_{0}, \gamma_{0}\right.$ and $\left.\delta_{1}\right)$, inter-reach variations were identified, even among geographically close populations, for $\gamma_{1}, \delta_{A d}$ and $\gamma_{A d}$. Spatial variation in density-dependent mortality was mostly explained by 3 reaches characteristics: shelter availability and inter-annual quantiles describing extreme water temperatures $\left(T_{10}\right.$ and $\left.T_{90}\right)$. In line with studies by Myrvold and Kennedy (2015) on steelhead self-thinning, the present results suggest that the strength of density-dependence is predictable from habitat characteristics.

\subsubsection{Shelter availability reduces the strength of density-dependence}

The clearest explanation of variation in density-dependence was increasing density-dependent mortality for the $1+$ age-stage with decreasing shelter availability. Most $\gamma_{1}$ values were low but increased when the reach had less than $2 \%$ of its area available as shelter, with maximal values when nearly no sheltered area was available (Fig. 5). A similar trend appeared to drive $\gamma_{A d}$ when one reach was removed. Future research should then also consider the influence of shelter availability on density-dependent mortality for the adult age-stage. The impact of shelter availability on mortality was previously reported in many papers, for brown trout (Armstrong et al. 2003; Dieterman and Hoxmeier 2011) or other salmonids (Finstad et al. 2007), and was used in the individual-based model developed by Van Winkle et al. (1998). The present results were also consistent with those reported by Baran (1995), who identified a decrease in maximal juvenile and adult brown trout density with decreasing shelter availability (especially below $2 \%$ availability). 
378

379

380

381

382

383

384

385

386

387

388

389

390

391

392

393

394

395

\subsubsection{Thermal regime influences the strength of density-dependence}

Density-dependent mortality for $1+$ brown trout increased for the lowest water temperature $\left(T_{90}<4^{\circ} \mathrm{C}\right)$. By contrast, density-dependent mortality for adult brown trout seemed to increase with high water temperature (Fig. 5). This might explain why 1+ density-dependent mortality was more often found in northern (e.g., Vøllestad and Olsen 2008) than in southern streams (e.g., Lobón-Cerviá 2012). Studies conducted in southern streams clearly identified density-dependence in adults (Lobón-Cerviá 2012). The higher fitted values for $\gamma_{A d}$ compared to $\gamma_{1}$ also explained why this process was easier to observe in previous studies. Temperature influence on density dependence may be explained by its effects on metabolism (Elliott 1976; Coutant 1976), swimming performance (Railsback et al. 2009) and foraging efficiency (Watz and Piccolo 2011). For example, swimming speed varies non-linearly with temperature, peaking at temperatures around a median temperature range of about $15^{\circ} \mathrm{C}$ (Railsback et al. 2009). We also suggested that higher water temperature might increase the activity of adult brown trout, leading to aggressive territorial behaviors.

\subsubsection{Understanding inter-reach variation in $\delta_{A d}$}

We were not able to explain the observed inter-reach variation in adult density-independent mortality $\left(\delta_{A d}\right)$. However, variation in this parameter (Fig. 5, first row) was largely driven by 2 reaches with exceptionally high posterior estimates (posterior means of $\delta_{A d}>0.05$ ), while most reaches presented lower estimates $(33$ reaches showed posterior means $<0.015)$. The two outlying reaches were distant from each other and had different physical characteristics (a wide natural reach draining $250 \mathrm{~km}^{2}$ and a reach below a dam, draining only $9 \mathrm{~km}^{2}$ ). Inter-reach variation in $\delta_{A d}$ might then result from factors that were not monitored, such as a contrast in angling pressure or variation in population dynamics induced by removal of individuals (Almodovar and Nicola 2004).

\subsubsection{Reach characteristics unrelated to change in mortality}

The weak effect of habitat sustainability index $(H S I)$ was to be expected, as HSI was designed to predict aggregate indicators of fish population status (biomass, or carrying capacity) rather than specific demographic processes (Hayes et al. 2009). While position in the stream network was previously used as an indicator of the suitability of a reach for a specific species or age-stage (e.g., 
Chaumot et al. 2003), median width was unrelated to mortality in the present data. Finally, the height

406

407

(and thus presence) of an upstream dam did not affect mean mortality processes downstream. When dams have existed for decades, it is likely that populations have adapted to the conditions induced by the dam. Moreover, many features of population dynamics other than mortality were not studied here, and might be influenced by the presence of an upstream dam (e.g., access to suitable spawning areas, sensitivity to environmental conditions).

\subsection{Limitations of our modeling approach and possible extension}

The present model focused on density-dependence and inter-reach variation in mortality. However, more processes could easily be added to the model. Hierarchical Bayesian modeling is especially suited to combining varied sources of information and sub-models (e.g., following Lecomte and Laplanche 2012 or Rochette et al. 2013). Therefore, it is important to identify which key processes could be integrated in the present model to enhance its ecological realism.

\subsubsection{Adding abiotic processes}

The present model included abiotic $0+$ mortality linked to flow velocity during emergence (p3), which captured rare extreme mortality events. However, consistently with the literature showing that variations in $0+$ density is mainly driven by intricate combinations of environmental conditions (e.g., Unfer et al. 2011; Lobón-Cerviá 2014), our model revealed a very low predictive power of 0+ density (high process stochasticity in $0+$, seen through $\sigma_{0}$ ). Analysis of temporal variation in $0+$ density would likely be improved by modeling additional abiotic processes of direct mortality. For example, including frequency or duration of high or low flows (Lobón-Cerviá 2009) or streambed mobility (Unfer et al. 2011; Bret et al. 2015) could improve modeling of 0+ density. Abiotic processes used in other modeling approaches, such inSTREAM (Railsback et al. 2009; e.g., direct influence of high temperature or reduced habitat availability) or MODYPOP (Gouraud et al. 2008; e.g., direct influence of flushing or high-flow in periods other than emergence), could also be considered. 


\subsubsection{Modeling growth and movement}

430 Beyond these additional influences, considering processes such as growth or movement would consist 431 in interesting future research avenues. Because growth and survival are linked, adding growth dynamics would likely improve the comprehension of brown trout population dynamics (e.g., Ebersole et al. 2009; Nislow and Armstrong 2012).

The present model considered all reaches as closed systems, although downstream drift of young individuals (Daufresne et al. 2005) and upstream migration of spawners (Young et al. 2010; Vøllestad et al. 2012) have been reported for brown trout. Consequently, the present mortality estimates covered both actual mortality and displacement. For instance, low mortality during the first year of life might be linked to partial replacement of dead individuals by migrants from upstream or tributaries, and may hide a complex source-sink dynamic among reaches. Modeling movement is challenging. One approach could be to integrate individual mark-recapture data in the population dynamics model through an integrated population model (Schaub et al. 2007; Schaub and Abadi 2011; Letcher et al. 2015). However, movement can be complicated by reach characteristics such as degree of longitudinal connectivity (presence of a dam or natural barrier, configuration of tributaries).

\subsubsection{Improving the representation of mortality during emergence}

Available data do not allowed us to model the variation of mortality during emergence among reaches. Additional information on spawning and emergence processes (e.g., local observations of fecundity according to spawner mass, frequent evaluation of recruits' survival) would help modeling variations among reaches.

\subsubsection{Modeling variation in stage duration among populations}

Contrary to Lobón-Cerviá et al. (2012) who suggested that the number and duration of age-stages might differ among populations, the number and duration of the processes underlying the life-cycle were assumed equal for all populations in our model. The 3 reaches located in Brittany and Normandy presented very different physical characteristics (e.g., smaller streambed particles, lower elevation and higher water temperature), and would likely have different dynamics as the other reaches. 
mountains (Gouraud et al. 2001) revealed that brown trout tended to be larger and shorter-lived in Brittany. However, these populations did not appear as outliers in the present data, and were well integrated in the hierarchical model: the differences in juvenile and adult mortality were explained by their reach characteristics. Nonetheless, $0+$ densities were over-estimated for these 3 reaches, confirming differences in spawning and early-life processes.

Integration of density-dependence is crucial to explaining juvenile and adult mortality, especially where little shelter is available in a reach. The results also highlighted the influence of water temperature on density-dependence strength. The model could help to predict change in monthly mortality in juveniles and adults under scenarios of global warming and changes in shelter availability due to habitat degradation or restoration (example for mean initial densities: Fig. 8). For instance, an increase in density (stocking) might not result in a long-term increase in population level in unfavorable reaches (low shelter availability), due to strong density-dependent mortality. Increasing available shelter area is, on the other hand, likely to reduce competition among juveniles and increase population levels. With further developments, the present model might become a useful tool to help management decision-making, to test scenarios in natural and regulated reaches. It will, however, be necessary to enhance the model's ability to capture temporal variations before considering predictions.

\section{Acknowledgement}

We thank the numerous people (working at ONEMA, Electricite de France, IRSTEA, ECOGEA, angling associations and other consulting firms) who contributed to electrofishing and habitat measurements. We also thank the organizations which provided environmental data (ONEMA, Météo France, and angling associations). 


\section{References}

480

Almodovar, A., and Nicola, G.G. 2004. Angling impact on conservation of Spanish stream-dwelling brown trout Salmo trutta. Fisheries Management and Ecology 11(3-4): 173-182.

Armstrong, J.D., Kemp, P.S., Kennedy, G.J.A., Ladle, M., and Milner, N.J. 2003. Habitat requirements of Atlantic salmon and brown trout in rivers and streams. Fish. Res. 62(2): 143-170.

Baglinière, J.L., and Maisse, G. 1991. La truite - Biologie et écologie. INRA Editions.

Baran, P. 1995. Analyse de la variablité des abondances de truites communes (Salmo trutta L.) dans les Pyrénées centrales françaises.

Bardonnet, A., and Prévost, E. 1994. Survie sous gravier de la truite (Salmo trutta) dans un affluent du Scorff. Internal report, AIP Eau, INRA Rennes.

Beverton, R.J.H., and Holt, S.J. 1957. On the dynamics of exploited fish populations. Chapman \& Hall, London, UK.

Borsuk, M.E., Reichert, P., Peter, A., Schager, E., and Burkhardt-Holm, P. 2006. Assessing the decline of brown trout (Salmo trutta) in Swiss rivers using a Bayesian probability network. Ecological Modelling 192(1-2): 224-244.

Bret, V., Bergerot, B., Capra, H., Gouraud, V., and Lamouroux, N. 2015. Influence of discharge, hydraulics, water temperature and dispersal on density synchrony in brown trout populations (Salmo trutta). Can. J. Fish. Aquat. Sci. 73(3): 319-329.

Brickhill, D., Evans, P.G.H., and Reid, J.M. 2015. Spatio-temporal variation in European starling reproductive success at multiple small spatial scales. Ecology and Evolution 5(16): 3364-3377.

Brooks, S.P., and Gelman, A. 1998. General Methods for Monitoring Convergence of Iterative Simulations. Journal of Computational and Graphical Statistics 7(4): 434-455.

Buckland, S.T., Newman, K.B., Fernandez, C., Thomas, L., and Harwood, J. 2007. Embedding Population Dynamics Models in Inference. 44-58.

Buckland, S.T., Newman, K.B., Thomas, L., and Koesters, N.B. 2004. State-space models for the dynamics of wild animal populations. Ecological Modelling 171(1-2): 157-175.

Buenau, K.E., Hiller, T.L., and Tyre, A.J. 2014. Modelling the effects of river flow on population dynamics of piping plovers (Charadrius melodu) and least terns (Sternula antillarum) nesting on the Missouri river. River. Res. Applic. 30(8): 964-975.

Caissie, D. 2006. The thermal regime of rivers: a review. Freshw. Biol. 51(8): 1389-1406.

Carle, R.T., and Strub, M.R. 1978. A new method for estimating population size from removal data. Biometrics 34(4): 621-630.

Cattanéo, F., Lamouroux, N., Breil, P., and Capra, H. 2002. The influence of hydrological and biotic processes on brown trout (Salmo trutta) population dynamics. Can. J. Fish. Aquat. Sci. 59: 12-22. CEN. 2003. Water quality - sampling of fish with electricity. European Standard.

Chaumot, A., Charles, S., Flammarion, P., and Auger, P. 2003. Ecotoxicology and spatial modeling in population dynamics: An illustration with brown trout. Environmental Toxicology and Chemistry 22(5): 958-969.

Coulson, T., Albon, S., Pilkington, J., and Clutton-Brock, T. 1999. Small-scale spatial dynamics in a fluctuating ungulate population. J. Anim. Ecol. 68(4): 658-671.

Coutant, C.C. 1976. Thermal effects on fish ecology. In Encyclopedia of Environmental Science and Engineering. Gordon and Breach Publishers. pp. 891-896.

Dauer, J.T., McEvoy, P.B., and Van Sickle, J. 2012. Controlling a plant invader by targeted disruption of its life cycle. Journal of Applied Ecology 49(2): 322-330.

Daufresne, M., Capra, H., and Gaudin, P. 2005. Downstream displacement of post-emergent brown trout: effects of development stage and water velocity. J. Fish Biol. 67(3): 599-614.

Daufresne, M., and Renault, O. 2006. Population fluctuations, regulation and limitation in streamliving brown trout. Oikos 113(3): 459-468.

Dieterman, D.J., and Hoxmeier, R.J.H. 2011. Demography of Juvenile and Adult Brown Trout in Streams of Southeastern Minnesota. Trans. Am. Fish. Soc. 140(6): 1642-1656. 
Dunbar, M.J., Alfredsen, K., and Harby, A. 2012. Hydraulic-habitat modelling for setting environmental river flow needs for salmonids. Fisheries Management and Ecology 19(6): 500-517. Ebersole, J.L., Colvin, M.E., Wigington, P.J., Leibowitz, S.G., Baker, J.P., Church, M.R., Compton, J.E., and Cairns, M.A. 2009. Hierarchical Modeling of Late-Summer Weight and Summer Abundance of Juvenile Coho Salmon across a Stream Network. Trans. Am. Fish. Soc. 138(5): 1138-1156. Elliott, J.A., and Hurley, M.A. 1998. Population regulation in adult, but not juvenile, resident trout (Salmo trutta) in a Lake District stream. J. Anim. Ecol. 67(2): 280-286. Elliott, J.M. 1976. The Energetics of Feeding, Metabolism and Growth of Brown Trout (Salmo trutta L.) in Relation to Body Weight, Water Temperature and Ration Size. J. Anim. Ecol. 45(3): 923-948. Elliott, J.M. 1994. Quantitative ecology and the brown trout. Oxford University Press, Oxford GBR. Fernandez-Chacon, A., Genovart, M., Alvarez, D., Cano, J.M., Ojanguren, A.F., Rodriguez-Munoz, R., and Nicieza, A.G. 2015. Neighbouring populations, opposite dynamics: influence of body size and environmental variation on the demography of stream-resident brown trout (Salmo trutta). Oecologia 178(2): 379-389. Finstad, A.G., Einum, S., Forseth, T., and Ugedal, O. 2007. Shelter availability affects behaviour, sizedependent and mean growth of juvenile Atlantic salmon. Freshw. Biol. 52(9): 1710-1718. George, E.I., and McCulloch, R.E. 1993. Variable Selection via Gibbs Sampling. Journal of the American Statistical Association 88(423): 881-889. Ginot, V., Souchon, Y., Capra, H., Breil, P., and Valentin, S. 1998. Logiciel EVHA 2.0. Evaluation de Territoire et de l'Environnement.

Gouraud, V., Baglinière, J.L., Baran, P., Sabaton, C., Lim, P., and Ombredane, D. 2001. Factors regulating brown trout populations in two french rivers: Application of a dynamic population model. Regul. River. 17: 557-569.

Gouraud, V., Baran, P., Bardonnet, A., Beaufrère, C., Capra, H., Caudron, A., Delacoste, M., Lescaux, J.M., Naura, M., Ovidio, M., Poulet, N., Tissot, L., Sebaston, C., and Baglinière, J.-L. 2014. Sur quelles connaissances se baser pour évaluer l'état de santé des populations de truite commune (Salmo trutta)? Hydroécologie Appliquée: 1-28.

Gouraud, V., Capra, H., Sabaton, C., Tissot, L., Lim, P., Vandewalle, F., Fahrner, G., and Souchon, Y. 2008. Long-term simulations of the dynamics of trout populations on river reaches bypassed by hydroelectric installations-analysis of the impact of different hydrological scenarios. River. Res. Applic. 24(9): 1185-1205.

Harwood, J., and Stokes, K. 2003. Coping with uncertainty in ecological advice: lessons from fisheries. Trends in Ecology \& Evolution 18(12): 617-622.

Hayes, D., Jones, M., Lester, N., Chu, C., Doka, S., Netto, J., Stockwell, J., Thompson, B., Minns, C., Shuter, B., and Collins, N. 2009. Linking fish population dynamics to habitat conditions: insights from the application of a process-oriented approach to several Great Lakes species. Rev Fish Biol Fisheries 19(3): 295-312.

Hayes, J.W. 1995. Spatial and temporal variation in the relative density and size of juvenile brown trout in the Kakanui River, North Otago, New Zealand. New Zeal. J. Mar. Fresh. 29(3): 393-407.

Hayes, J.W., Olsen, D.A., and Hay, J. 2010. The influence of natural variation in discharge on juvenile brown trout population dynamics in a nursery tributary of the Motueka River, New Zealand. New Zeal. J. Mar. Fresh. 44(4): 247-269.

Heggenes, J. 1996. Habitat selection by brown trout (Salmo trutta) and young atlantic salmon (S. salar) in streams : Static and dynamic hydraulic modelling. Regul. River. 12(2-3): 155-169.

Heggenes, J., and Traaen, T. 1988. Downstream migration and critical water velocities in stream channels for fry of four salmonid species. J. Fish Biol. 32(5): 717-727.

Joly, K., Klein, D.R., Verbyla, D.L., Rupp, T.S., and Chapin, F.S. 2011. Linkages between large-scale climate patterns and the dynamics of Arctic caribou populations. Ecography 34(2): 345-352.

Kanno, Y., Pregler, K.C., Hitt, N.P., Letcher, B.H., Hocking, D.J., and Wofford, J.E.B. 2016. Seasonal temperature and precipitation regulate brook trout young-of-the-year abundance and population dynamics. Freshw. Biol. 61(1): 88-99. 
Keith, P., Persat, H., Feunteun, E., and Allardi, J. 2011. Les Poissons d'eau douce de France. Klemetsen, A., Amundsen, P.A., Dempson, J.B., Jonsson, B., Jonsson, N., O'Connell, M.F., and Mortensen, E. 2003. Atlantic salmon Salmo salar L., brown trout Salmo trutta L. and Arctic charr Salvelinus alpinus (L.): a review of aspects of their life histories. Ecol. Freshw. Fish 12: 1-59.

Lamouroux, N., and Capra, H. 2002. Simple predictions of instream habitat model outputs for target fish populations. Freshw. Biol. 47: 1543-1556.

Lecomte, J.-B., and Laplanche, C. 2012. A length-based hierarchical model of brown trout (Salmo trutta fario) growth and production. Biometrical Journal 54(1): 108-126.

Lek, S. 2007. Uncertainty in ecological models. Ecological Modelling 207(1): 1-2.

Letcher, B.H., Schueller, P., Bassar, R.D., Nislow, K.H., Coombs, J.A., Sakrejda, K., Morrissey, M., Sigourney, D.B., Whiteley, A.R., O'Donnell, M.J., and Dubreuil, T.L. 2015. Robust estimates of environmental effects on population vital rates: an integrated capture-recapture model of seasonal brook trout growth, survival and movement in a stream network. J Anim Ecol 84(2): 337-352.

Li, Y., and Jiao, Y. 2015. Evaluation of stocking strategies for endangered white abalone using a hierarchical demographic model. Ecological Modelling 299: 14-22.

Lobón-Cerviá, J. 2009. Why, when and how do fish populations decline, collapse and recover? The example of brown trout (Salmo trutta) in Rio Chaballos (northwestern Spain). Freshw. Biol. 54(6): 1149-1162.

Lobón-Cerviá, J. 2012. Density-dependent mortality in adults, but not juveniles, of stream-resident brown trout (Salmo trutta). Freshw. Biol. 57(10): 2181-2189.

Lobón-Cerviá, J. 2014. Recruitment and survival rate variability in fish populations: densitydependent regulation or further evidence of environmental determinants? Can. J. Fish. Aquat. Sci. 71(2): 290-300.

Lobón-Cerviá, J., Budy, P., and Mortensen, E. 2012. Patterns of natural mortality in stream-living brown trout (Salmo trutta). Freshw. Biol. 57(3): 575-588.

Lobon-Cervia, J., and Rincon, P.A. 2004. Environmental determinants of recruitment and their influence on the population dynamics of stream-living brown trout Salmo trutta. Oikos 105(3): 641646.

McMahon, S.M., Dietze, M.C., Hersh, M.H., Moran, E.V., and Clark, J.S. 2009. A Predictive Framework to Understand Forest Responses to Global Change. Annals of the New York Academy of Sciences 1162(1): 221-236.

Michielsens, C.G.J., McAllister, M.K., Kuikka, S., Mäntyniemi, S., Romakkaniemi, A., Pakarinen, T., Karlsson, L., and Uusitalo, L. 2008. Combining multiple Bayesian data analyses in a sequential framework for quantitative fisheries stock assessment. Can. J. Fish. Aquat. Sci. 65(5): 962-974. Myrvold, K.M., and Kennedy, B.P. 2015. Local habitat conditions explain the variation in the strength of self-thinning in a stream salmonid. Ecology and Evolution 5(16): 3231-3242.

Newman, K., Buckland, S.T., Morgan, B., King, R., Borchers, D.L., Cole, D., Besbeas, P., Gimenez, O., and Thomas, L. 2014. Modelling Population Dynamics. Springer-Verlag New York.

Nicola, G.G., Almodóvar, A., Jonsson, B., and Elvira, B. 2008. Recruitment variability of resident brown trout in peripheral populations from southern Europe. Freshw. Biol. 53(12): 2364-2374.

Nislow, K.H., and Armstrong, J.D. 2012. Towards a life-history-based management framework for the effects of flow on juvenile salmonids in streams and rivers. Fisheries Management and Ecology 19(6): 451-463.

O'Hara, R.B., and Sillanpaa, M.J. 2009. A review of Bayesian variable selection methods: what, how and which. 85-117.

Parent, E., and Rivot, E. 2013. Introduction to Hierarchical Bayesian Modeling for Ecological Data. Chapman and Hall/CRC

Petitgas, P., Rijnsdorp, A.D., Dickey-Collas, M., Engelhard, G.H., Peck, M.A., Pinnegar, J.K., Drinkwater, K., Huret, M., and Nash, R.D.M. 2013. Impacts of climate change on the complex life cycles of fish. Fisheries Oceanography 22(2): 121-139. 
Piffady, J., Parent, É., and Souchon, Y. 2013. A hierarchical generalized linear model with variable selection: studying the response of a representative fish assemblage for large European rivers in a multi-pressure context. Stoch Environ Res Risk Assess 27(7): 1719-1734.

Plummer, M., Stukalov, A., and Denwood, M. 2015. rjags 3-15.

Poff, L.N., Olden, J.D., Merritt, D.M., and Pepin, D.M. 2007. Homogenization of regional river dynamics by dams and global biodiversity implications. Proc Natl Acad Sci U S A 104(14): 5732-5737. Quinn, T.J., and Deriso, R.B. 1999. Quantitative fish dynamics. Oxford University Press, New York. Railsback, S.F., Harvey, B.C., Jackson, S.K., and Lamberson, R.H. 2009. InSTREAM: the individual-based stream trout research and environmental assessment model. Gen. Tech. Rep., Albany, CA: U.S. Department of Agriculture, Forest Service, Pacific Southwest Research Station.

Ricker, W.E. 1954. Stock and Recruitment. Journal of the Fisheries Research Board of Canada 11(5): 559-623.

Rivot, E., and Prévost, E. 2002. Hierarchical Bayesian analysis of capture-mark-recapture data. Can. J. Fish. Aquat. Sci. 59(11): 1768-1784.

Rivot, E., Prévost, E., Parent, E., and Baglinière, J.L. 2004. A Bayesian state-space modelling framework for fitting a salmon stage-structured population dynamic model to multiple time series of field data. Ecological Modelling 179(4): 463-485.

Rochette, S., Le Pape, O., Vigneau, J., and Rivot, E. 2013. A hierarchical Bayesian model for embedding larval drift and habitat models in integrated life cycles for exploited fish. Ecol. Appl. 23(7): 1659-1676.

Sabaton, C., and Miquel, J. 1993. La méthode des micro-habitats : un outil d'aide au choix d'un débit réservé à l'aval des ouvrages hydroélectriques. Expérience d'Electricité de France. Hydroécologie appliquée 5(1): 127-163

Sabaton, C., Souchon, Y., Capra, H., Gouraud, V., Lascaux, J.M., and Tissot, L. 2008. Long-term brown trout populations responses to flow manipulation. River. Res. Applic. 24(5): 476-505.

Schaub, M., and Abadi, F. 2011. Integrated population models: a novel analysis framework for deeper insights into population dynamics. Journal of Ornithology 152(S1): 227-237.

Schaub, M., Gimenez, O., Sierro, A., and Arlettaz, R. 2007. Use of Integrated Modeling to Enhance Estimates of Population Dynamics Obtained from Limited Data. Conservation Biology 21(4): 945-955. Simmonds, E.J., Portilla, E., Skagen, D., Beare, D., and Reid, D.G. 2010. Investigating agreement between different data sources using Bayesian state-space models: an application to estimating NE Atlantic mackerel catch and stock abundance. ICES Journal of Marine Science: Journal du Conseil 67(6): 1138-1153.

Swain, D.P., Jonsen, I.D., Simon, J.E., and Myers, R.A. 2009. Assessing threats to species at risk using stage-structured state-space models: mortality trends in skate populations. Ecol. Appl. 19(5): 13471364.

Tharme, R.E. 2003. A global perspective on environmental flow assessment : emerging trends in the development and application of environmental flow methodologies for rivers. River. Res. Applic. 19: 397-441.

Tissot, L., Bret, V., Capra, H., Baran, P., and Gouraud, V. 2016. Main potential drivers of trout population dynamics in bypassed stream sections. Ecol. Freshw. Fish.

Unfer, G., Hauer, C., and Lautsch, E. 2011. The influence of hydrology on the recruitment of brown trout in an Alpine river, the Ybbs River, Austria. Ecol. Freshw. Fish 20(3): 438-448.

Van Winkle, W., Jager, Y., and Holcomb, B. 1998. An individual-based model for sympatric populations of brown and rainbow trout. Oak ridge national laboratory, Oak ridge.

Vøllestad, L.A., and Olsen, E.M. 2008. Non-additive effects of density-dependent and densityindependent factors on brown trout vital rates. Oikos 117(11): 1752-1760.

Vøllestad, L.A., Serbezov, D., Bass, A., Bernatchez, L., Olsen, E.M., and Taugbøl, A. 2012. Small-scale dispersal and population structure in stream-living brown trout (Salmo trutta) inferred by markrecapture, pedigree reconstruction, and population genetics. Can. J. Fish. Aquat. Sci. 69(9): 15131524. 
682

683

684

685

686

687

688

689

\begin{tabular}{lccc}
\hline Physical characteristics & Min & Mean & Max \\
\hline Width at median discharge $L_{50}(\mathrm{~m})$ & 2.9 & 8.1 & 15.5 \\
Reach slope (\%) & 0.3 & 3.3 & 13.2 \\
Elevation (m) & 15.0 & 814.1 & 1370.0 \\
Distance from source $(\mathrm{km})$ & 3.0 & 17.6 & 49.0 \\
Basin area $\left(\mathrm{km}^{2}\right)$ & 9.0 & 131.5 & 605.0 \\
Median daily discharge $\mathrm{Q}_{50}\left(\mathrm{~m}^{3} \cdot \mathrm{s}^{-1}\right)$ & 0.1 & 1.0 & 2.8 \\
Reach flow velocity $\left(\mathrm{m} . \mathrm{s}^{-1}\right)$ at $\mathrm{Q}_{50}$ & 0.1 & 0.4 & 0.8 \\
Median daily water temperature $T_{50}\left({ }^{\circ} \mathrm{C}\right)$ & 5.8 & 8.1 & 11.3 \\
Shelter availability $(\%$ of the total wetted area) & 0.27 & 2.21 & 6.45 \\
Habitat Suitability Index $\left(0+\right.$ and $1+$ brown trout) at $\mathrm{Q}_{50}$ & 0.2 & 0.4 & 0.7 \\
Habitat Suitability Index $\left(\right.$ adult brown trout) at $\mathrm{Q}_{50}$ & 0.0 & 0.2 & 0.4 \\
\hline
\end{tabular}

Watz, J., and Piccolo, J.J. 2011. The role of temperature in the prey capture probability of driftfeeding juvenile brown trout (Salmo trutta). Ecol. Freshw. Fish 20(3): 393-399.

Young, R.G., Hayes, J.W., Wilkinson, J., and Hay, J. 2010. Movement and mortality of adult brown trout in the Motupiko River, New Zealand: effects of water temperature, flow, and flooding. Trans. Am. Fish. Soc. 139(1): 137-146.

\section{Tables}

Table 1. Physical characteristics of the 40 stream reaches.

690

691 


\begin{tabular}{clll}
\hline Parameter & Definition & Source & Prior distribution \\
\hline$\varphi$ & Sex-ratio & Lobon-Cervia and Rincon 2004; & Beta(200,200) \\
& & Gouraud et al. 2014 & \\
$\psi$ & Fecundity (eggs.kg $\left.{ }^{-1}\right)$ & Keith et al. 2011; Gouraud et al. & Log-N(7.6, 0.005) \\
& & 2008; Gouraud et al. 2014 & \\
$\delta_{E g g}$ & Density-independent mortality & & Bardonnet and Prévost 1994 \\
& rate during egg incubation & & \\
& Density-dependent mortality & Gouraud et al. 2014; & Fixed to 0 \\
\hline
\end{tabular}

694

695 
696

698

Table 3. Definitions, related equations and prior distributions of all parameters for which updating was expected from the data. Indices $k$ denote age-stages, $c$ denote reach characteristics ( $c=T_{50}, L_{50}$, Shelt, HSI, hBarr; parameters defined in Table 4) and $\theta$ denotes parameters dependent on hyperparameters (N=Normal distribution; $\log N=\log$-Normal distribution).

\begin{tabular}{|c|c|c|c|}
\hline Parameter & Definition & $\begin{array}{l}\text { Related process } \\
\text { / equation }\end{array}$ & Prior distribution \\
\hline \multicolumn{4}{|c|}{ Global parameters } \\
\hline$\mu$ & $\begin{array}{l}\text { Excess-mortality rate induced by flow velocity }>Z \\
\text { during emergence }\left(\mathrm{m} \cdot \mathrm{s}^{-1}\right)\end{array}$ & p3 & $\operatorname{Beta}(1,1)$ \\
\hline$Z$ & $\begin{array}{l}\text { Threshold for flow-velocity mortality during } \\
\text { emergence }\left(\mathrm{m} \cdot \mathrm{s}^{-1}\right)\end{array}$ & p3 & $\operatorname{Gamma}(1,1)$ \\
\hline$\delta_{k}$ & $\begin{array}{l}\text { Global instantaneous density-independent mortality } \\
\text { rate }\end{array}$ & $\begin{array}{l}\text { p2 }(k=E g g) \\
\text { p4 }(k=E) \\
\text { p5 }(k=0) \\
\text { p6 }(k=1)\end{array}$ & $\log N(0,1)$ \\
\hline$\gamma_{k}$ & Global instantaneous density-dependent mortality rate & $\begin{array}{l}\mathrm{p} 4(k=E) \\
\mathrm{p} 5(k=0)\end{array}$ & $\log N(0,1)$ \\
\hline$\sigma_{k}$ & Process stochasticity & $(k=0,1, A d)$ & $\operatorname{Gamma}(1,1)$ \\
\hline \multicolumn{4}{|c|}{ Hyper-parameters } \\
\hline$\beta_{\theta, c}$ & $\begin{array}{l}\text { Slope of the link between } E_{\theta} \text { (expected mean of } \\
\text { parameter } \theta \text { ) and reach characteristic } c\end{array}$ & $\begin{array}{l}\text { Eq. } 3 \\
\left(\theta=\gamma_{1}, \delta_{A d}, \gamma_{A d}\right)\end{array}$ & See Eq. 4 \\
\hline$I_{c, \theta}$ & $\begin{array}{l}\text { Auxiliary variable indicating whether covariate } c \text { has } \\
\text { an influence }\left(I_{c, \theta}=1\right) \text { or not }\left(I_{c, \theta}=0\right) \text { on parameter } \theta\end{array}$ & $\begin{array}{l}\text { Eq. } 4 \\
\left(\theta=\gamma_{1}, \delta_{A d}, \gamma_{A d}\right)\end{array}$ & Bernoulli $(0.5)$ \\
\hline$B 0_{c, \theta}$ & $\begin{array}{l}\text { 'Spike' of the mixture distribution of } \beta_{\theta, c} \text { (used } \\
\text { when } I_{c, \theta}=0 \text { ) }\end{array}$ & $\begin{array}{l}\text { Eq. } 4 \\
\left(\theta=\gamma_{1}, \delta_{A d}, \gamma_{A d}\right)\end{array}$ & $\mathrm{N}(0, \tau)$ \\
\hline$B 1_{c, \theta}$ & $\begin{array}{l}\text { 'Slab' of the mixture distribution of } \beta_{\theta, c} \text { (used } \\
\text { when } I_{c, \theta}=1 \text { ) }\end{array}$ & $\begin{array}{l}\text { Eq. } 4 \\
\left(\theta=\gamma_{1}, \delta_{A d}, \gamma_{A d}\right)\end{array}$ & $\mathrm{N}(0, g \tau)$ \\
\hline$\alpha_{\theta}$ & Intercept for $E_{\theta}$ & $\begin{array}{l}\text { Eq. } 3 \\
\left(\theta=\gamma_{1}, \delta_{A d}, \gamma_{A d}\right)\end{array}$ & $\mathrm{N}(-1,2)$ \\
\hline$\sigma_{\theta}$ & Standard deviation for parameter $\theta$ & $\begin{array}{l}\text { Eq. } 2 \\
\left(\theta=\gamma_{1}, \delta_{A d}, \gamma_{A d}\right)\end{array}$ & $\operatorname{Gamma}(1,1)$ \\
\hline \multicolumn{4}{|c|}{ Parameters $\theta$ dependent on hyper-parameters } \\
\hline$\delta_{k}$ & $\begin{array}{l}\text { Hierarchical instantaneous density-independent } \\
\text { mortality rate }\end{array}$ & $\mathrm{p} 7 \& \mathrm{p} 8(k=A d)$ & $\log \mathrm{N}\left(E_{\delta_{k}}, \sigma_{\delta_{k}}\right)$ \\
\hline$\gamma_{k}$ & $\begin{array}{l}\text { Hierarchical instantaneous density-dependent mortality } \\
\text { rate }\end{array}$ & $\begin{array}{l}\mathrm{p} 6(k=1) \\
\mathrm{p} 7 \& \mathrm{p} 8(k=A d)\end{array}$ & $\log \mathrm{N}\left(E_{\gamma_{k}}, \sigma_{\gamma_{k}}\right)$ \\
\hline
\end{tabular}




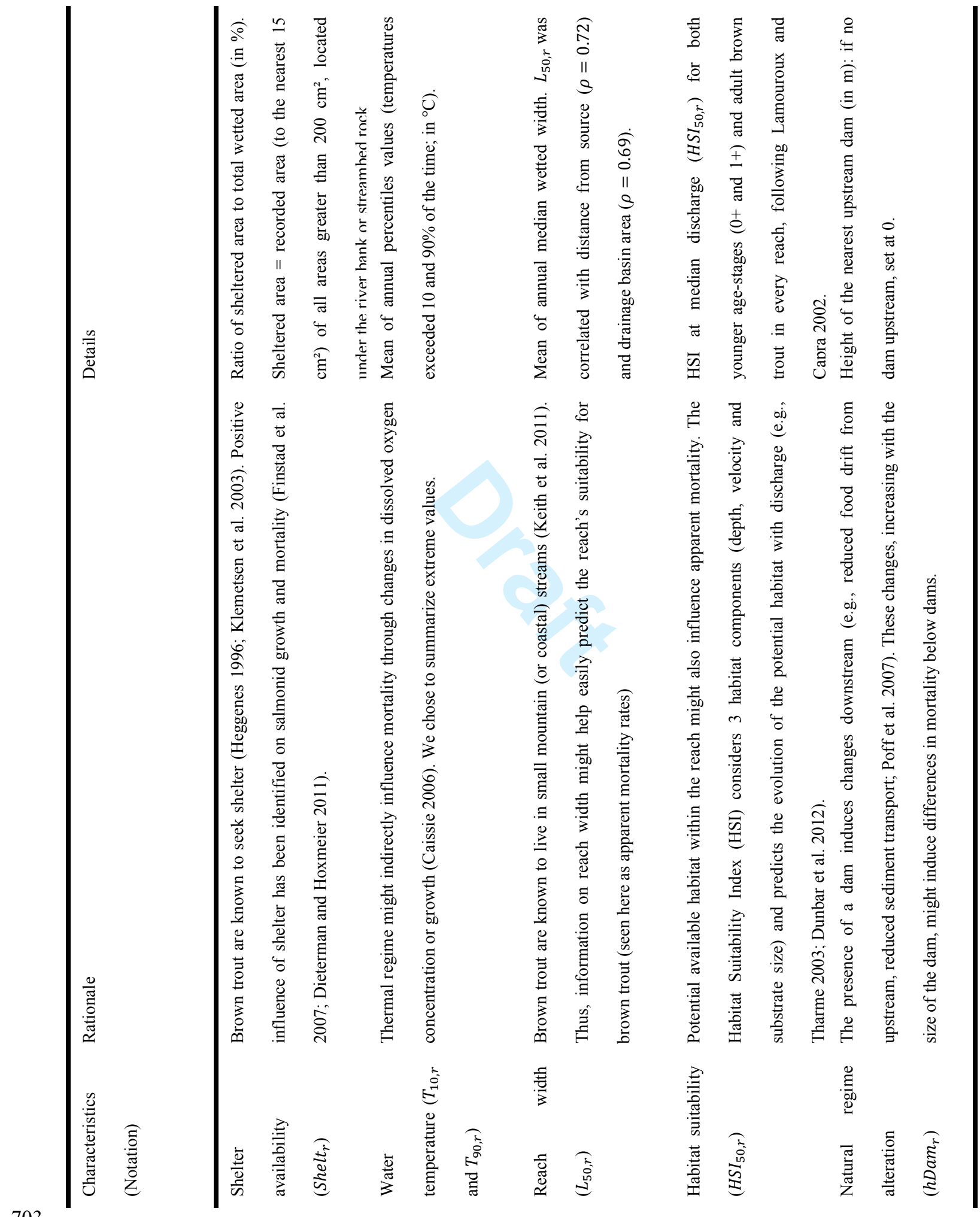


704 Table 5. Main statistics of the marginal posterior distributions for the parameters estimated across all reaches

705 and years.

\begin{tabular}{lcrrrrrr}
\hline Process & Parameter & Mean & $2.5 \%$ & $25 \%$ & Median & $75 \%$ & $97.5 \%$ \\
\hline p1 & $\psi$ & 1,993 & 1,734 & 1,900 & 1,989 & 2,086 & 2,278 \\
& $\varphi$ & 0.50 & 0.45 & 0.48 & 0.50 & 0.52 & 0.55 \\
\hline p2 & $\delta_{E g g}$ & 0.04 & 0.02 & 0.03 & 0.04 & 0.05 & 0.06 \\
\hline p3 & $\mu$ & 0.94 & 0.85 & 0.93 & 0.95 & 0.96 & 0.98 \\
& $Z$ & 1.15 & 1.10 & 1.14 & 1.15 & 1.17 & 1.21 \\
\hline p4 & $\delta_{E}$ & 0.24 & 0.04 & 0.12 & 0.21 & 0.33 & 0.62 \\
& $\gamma_{E}$ & 0.02 & 0.01 & 0.02 & 0.02 & 0.03 & 0.03 \\
\hline p5 & $\delta_{0}$ & $2.67 \mathrm{E}-03$ & $1.00 \mathrm{E}-03$ & $1.86 \mathrm{E}-03$ & $2.50 \mathrm{E}-03$ & $3.30 \mathrm{E}-03$ & $5.24 \mathrm{E}-03$ \\
& $\gamma_{0}$ & $1.22 \mathrm{E}-03$ & $5.73 \mathrm{E}-04$ & $9.54 \mathrm{E}-04$ & $1.19 \mathrm{E}-03$ & $1.45 \mathrm{E}-03$ & $2.02 \mathrm{E}-03$ \\
\hline p6 & $\delta_{1}$ & $2.95 \mathrm{E}-03$ & $1.09 \mathrm{E}-03$ & $2.07 \mathrm{E}-03$ & $2.77 \mathrm{E}-03$ & $3.64 \mathrm{E}-03$ & $5.78 \mathrm{E}-03$ \\
& $\alpha_{\gamma_{1}}$ & -6.94 & -8.15 & -7.23 & -6.88 & -6.58 & -6.10 \\
& $\beta_{\gamma_{1}, S h e l t}$ & -1.21 & -2.40 & -1.62 & -1.30 & -1.04 & -0.61 \\
& $\beta_{\gamma_{1}, \mathrm{~T} 90}$ & -0.60 & -1.48 & -0.93 & -0.70 & -0.50 & -0.12 \\
& $\sigma_{\gamma_{1}}$ & 0.98 & 0.36 & 0.75 & 0.95 & 1.17 & 1.74 \\
\hline p7, p8 & $\alpha_{\delta_{A d}}$ & -5.47 & -7.32 & -5.97 & -5.37 & -4.88 & -4.16 \\
& $\sigma_{\delta_{A d}}$ & 1.62 & 0.87 & 1.26 & 1.54 & 1.89 & 2.78 \\
& $\alpha_{\gamma_{A d}}$ & -4.84 & -5.12 & -4.93 & -4.84 & -4.75 & -4.59 \\
& $\beta_{\gamma_{A d}, \mathrm{~T} 10}$ & 0.35 & 0.08 & 0.24 & 0.32 & 0.40 & 0.56 \\
& $\sigma_{\gamma_{A d}}$ & 0.59 & 0.37 & 0.51 & 0.59 & 0.67 & 0.85 \\
\hline Process Stochasticity & $\sigma_{0}$ & 1.05 & 0.98 & 1.02 & 1.05 & 1.07 & 1.12 \\
& $\sigma_{1}$ & 0.63 & 0.58 & 0.61 & 0.63 & 0.64 & 0.67 \\
& $\sigma_{A d}$ & 0.41 & 0.38 & 0.39 & 0.40 & 0.42 & 0.44 \\
\hline
\end{tabular}

706

707 


\section{Figures}

709

710

711

712

713

714

715

716

717

718

719

720

721

722

723

724

725

726

727

728

729

730

731

Fig. 1. Locations of the 40 reaches (19 below dams).

Fig. 2. Life-cycle model for resident brown trout (S. trutta), split into 5 stages (Egg: eggs; E: emergent fry; 0: juvenile during the end of the first year; 1: 1+; Ad: adults) and 8 processes (black arrows) related to model equations (Appendix A). Gray boxes show the dates of transition between stages, set at the $15^{\text {th }}$ day of the month (3: March, 5: May, 12: December) of the year indicated in subscript (starting year $y=$ spawning year). Other subscripts denote spawning (Spw), initial state of an age-stage (i), and integrated mortality due to flow velocity (V) or sampling (Spl). The population was observed at sampling (during p5, p6 and p7). Adults (Ad) age-stage combined fish of several ages (2: fish in their $3^{\text {rd }}$ year of life, $>2$ : fish older than 3 years).

Fig. 3. Directed acyclic graph for the brown trout population dynamics model presented in Fig. 1. Variables represented in ellipses were defined by a probability distribution. White ellipses are non-observed variables; shaded ellipses are data. Shaded boxes represent fixed constant or calculated covariates. Solid-line arrows represent stochastic transitions; dotted-line arrows represent deterministic links (including age-stage transitions, structuring the life-cycle). The number of each process (p1-p8; detailed in Appendix A) is added.

Fig. 4. Posterior frequency of inclusion (in \%) of the effect of the 6 studied reach characteristics (rows) on the 3 mortality rates (columns). Table A shows the results of the model for the 40 reaches. Table $B$ summarizes the results of the leave-one-out deletion test, giving median [range] values for posterior frequency of inclusion. Gray scale is associated with the posterior frequency of inclusion.

Fig. 5. Marginal posterior distributions of density-independent $\left(\delta_{A d}\right)$ and density-dependent $\left(\gamma_{1}\right.$ and $\left.\gamma_{A d}\right)$ mortality rates modeled by a hierarchical structure for the 40 reaches. The $1^{\text {st }}$ row shows the distribution of $\delta_{A d}$, which could not be explained by reach characteristics. The $2^{\text {nd }}$ to $5^{\text {th }}$ rows show change in density-dependent mortality distribution $\left(\gamma_{1}\right.$ and $\left.\gamma_{A d}\right)$ with shelter availability and inter-annual mean of percentile of water temperatures $\left(T_{10}\right.$ and $\left.T_{90}\right)$ as covariates. 
732

733

734

735

736

737

738

739

740

741

742

743

744

745

746

747

748

Fig. 6. Total mortality for the processes describing natural mortality between successive age-stages ( $p 4$, p5, p6 and p7) for total process duration (respectively, 2, 10, 12 and 12 months). When inter-reach variation in at least one mortality rate $\left(\delta_{k}\right.$ or $\left.\gamma_{k}\right)$ was detected for age-stage $k$, fitted relations for the 40 reaches are presented (dashed gray lines) along with the mean expected relation (solid line). A vertical line is drawn at mean observed densities for 0+, $1+$ and adults (densities were never observed at emergence); upper limits of $x$-axes correspond to the 90th percentile of observed densities. Mortality from egg to emergent fry is not represented here, as mortality rates were not fitted but taken from the literature.

Fig. 7. Time series of observed and predicted densities of $0+, 1+$ and adult brown trout in 2 reaches (Bes and Senouire; columns). Points represent observed densities, associated with observation uncertainty (vertical lines). The black line shows the mean estimate of each year's predicted density. The shaded areas show the 50\% and 95\% confidence intervals for the predicted densities, when process error is considered.

Fig. 8. Prediction of monthly mortality in 1+ depending on shelter availability (x-axis) and inter-annual mean of a percentile of water temperatures $\left(T_{90}\right)$ (y-axis). Black dots show the characteristics of reaches considered in this paper. Marginal relations are shown in upper and right sub-panels (shaded areas show 50\% and 95\% confidence intervals). Monthly mortality was computed by considering both density-independent and densitydependent mortality and for mean initial densities (10.5 ind.100 $\mathrm{m}^{-2}$ for $1+$ and 8.1 ind.100 $\mathrm{m}^{-2}$ for adults). 


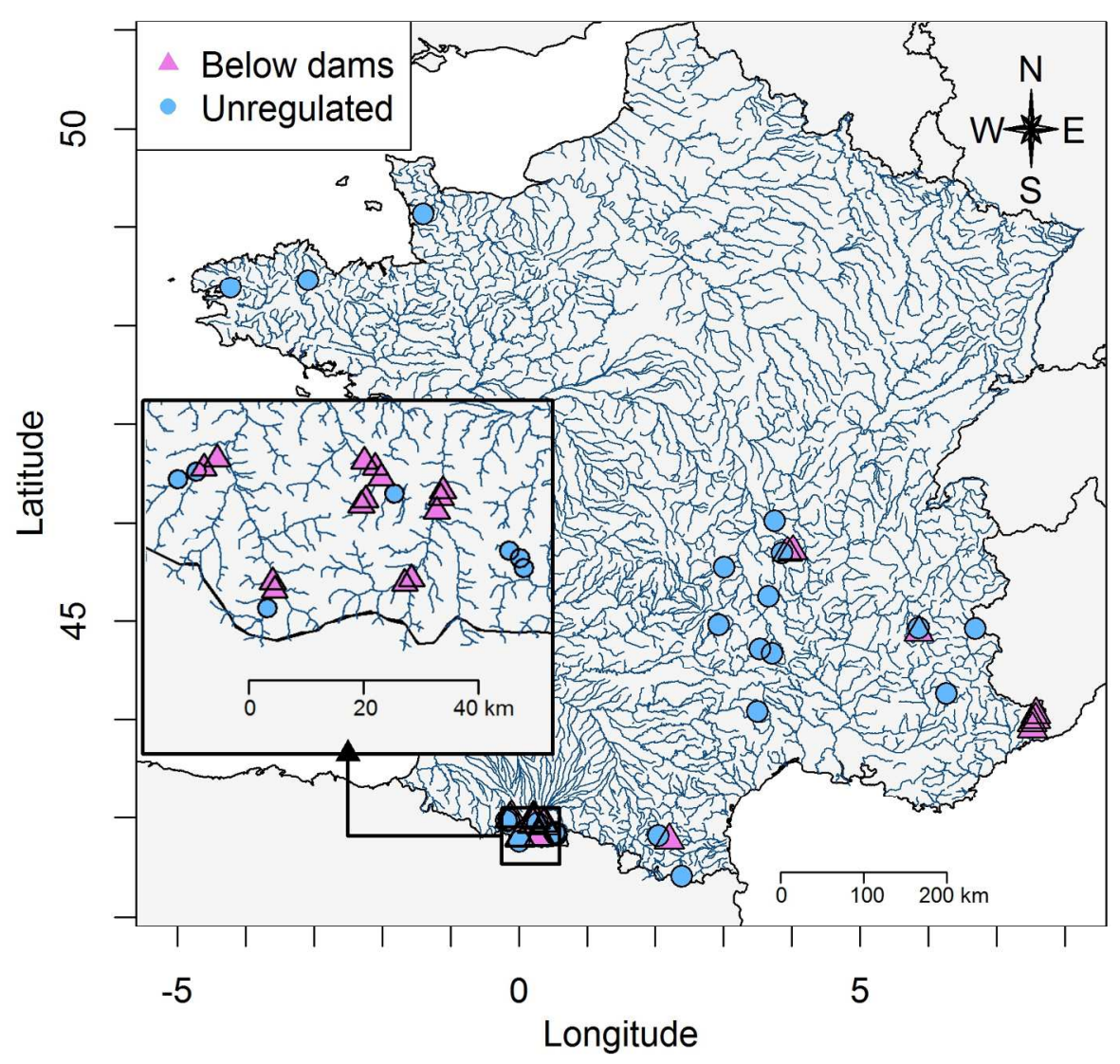

Locations of the 40 reaches ( 19 below dams).

$169 \times 159 \mathrm{~mm}(300 \times 300$ DPI $)$ 




Fig. 2. Life-cycle model for resident brown trout (S. trutta), split into 5 stages (Egg: eggs; E: emergent fry; 0 : juvenile during the end of the first year; $1: 1+;$ Ad: adults) and 8 processes (black arrows) related to model equations (Appendix A). Gray boxes show the dates of transition between stages, set at the 15 th day of the month (3: March, 5: May, 12: December) of the year indicated in subscript (starting year $y=$ spawning year). Other subscripts denote spawning (Spw), initial state of an age-stage (i), and integrated mortality due to flow velocity $(\mathrm{V})$ or sampling $(\mathrm{Spl})$. The population was observed at sampling (during p5, p6 and p7). Adults (Ad) age-stage combined fish of several ages (2: fish in their 3rd year of life, $>2$ : fish older than 3 years).

$289 \times 220 m m(96 \times 96$ DPI) 


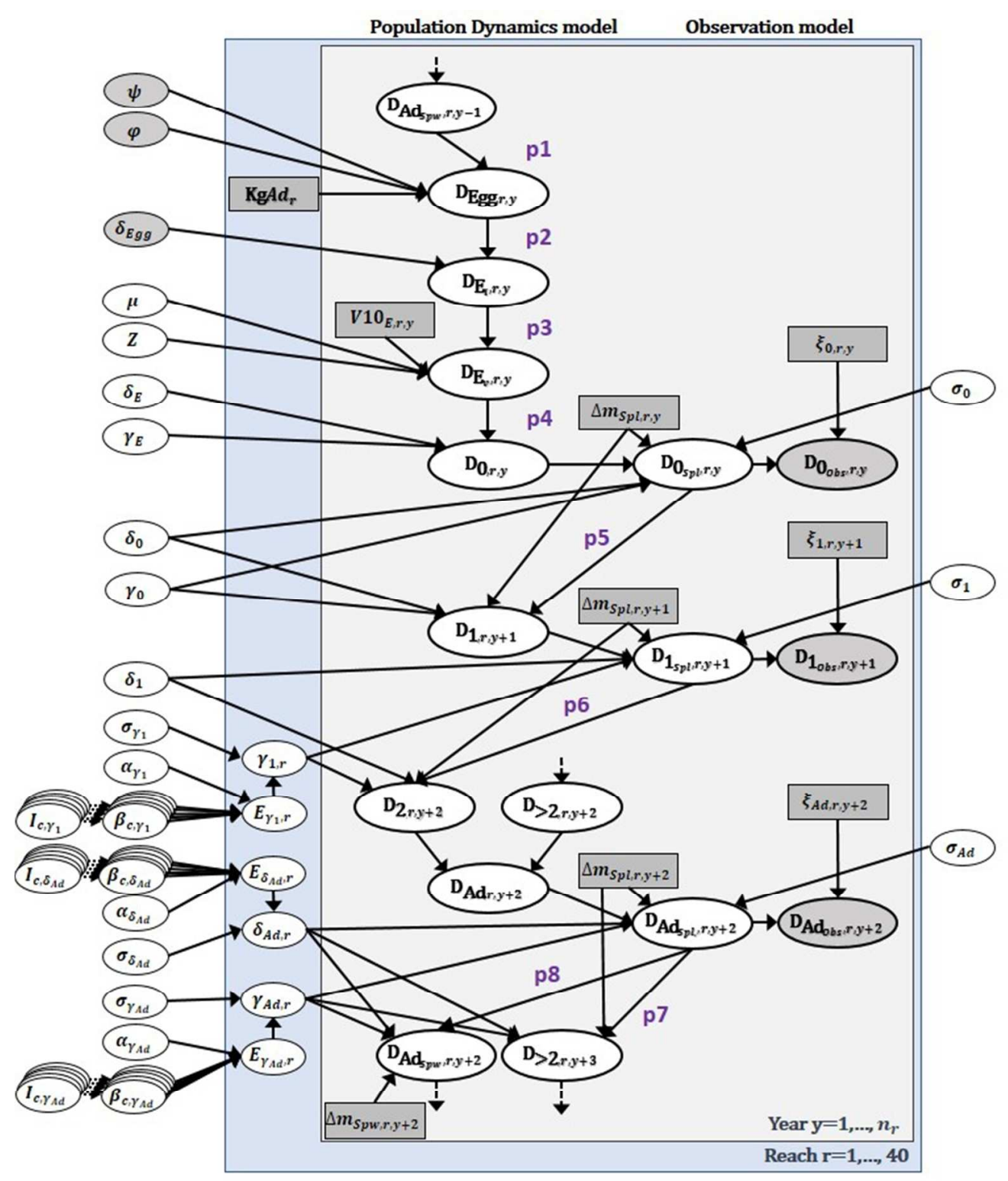

Fig. 3. Directed acyclic graph for the brown trout population dynamics model presented in Fig. 1. Variables represented in ellipses were defined by a probability distribution. White ellipses are non-observed variables; shaded ellipses are data. Shaded boxes represent fixed constant or calculated covariates. Solid-line arrows represent stochastic transitions; dotted-line arrows represent deterministic links (including age-stage transitions, structuring the life-cycle). The number of each process ( 1 - p8; detailed in Appendix A) is added. 


\begin{tabular}{|c|c|c|c|c|c|c|c|}
\hline A. & $\delta_{\mathrm{Ad}}$ & $\gamma_{1}$ & $\gamma_{\text {Ad }}$ & B. & $\delta_{\text {Ad }}$ & $\gamma_{1}$ & $\gamma_{\text {Ad }}$ \\
\hline Shelt $_{r}$ & 17 & 85 & 27 & Shelt $_{r}$ & $\begin{array}{c}18 \\
{[13-23]}\end{array}$ & $\begin{array}{c}87 \\
{[75-95]}\end{array}$ & $\begin{array}{c}24 \\
{[6-71]}\end{array}$ \\
\hline $\mathrm{T}_{10, \mathrm{r}}$ & 23 & 11 & 74 & $\mathrm{~T}_{10, \mathrm{r}}$ & $\begin{array}{c}27 \\
{[20-37]}\end{array}$ & $\begin{array}{c}9 \\
{[7-20]}\end{array}$ & $\begin{array}{c}77 \\
{[35-98]}\end{array}$ \\
\hline$T_{90, r}$ & 21 & 70 & 12 & $\mathrm{~T}_{90, \mathrm{r}}$ & $\begin{array}{c}18 \\
{[15-21]}\end{array}$ & $\begin{array}{c}64 \\
{[38-90]}\end{array}$ & $\begin{array}{c}11 \\
{[7-20]}\end{array}$ \\
\hline $\mathrm{L}_{50, \mathrm{r}}$ & 30 & 20 & 9 & $\mathrm{~L}_{50, \mathrm{r}}$ & $\begin{array}{c}31 \\
{[13-42]}\end{array}$ & $\begin{array}{c}18 \\
{[11-33]}\end{array}$ & $\begin{array}{c}9 \\
{[3-14]}\end{array}$ \\
\hline $\mathrm{HSI}_{50, \mathrm{r}}$ & 18 & 10 & 6 & $\mathrm{HSI}_{50, \mathrm{r}}$ & $\begin{array}{c}19 \\
{[16-31]}\end{array}$ & $\begin{array}{c}10 \\
{[8-14]}\end{array}$ & $\begin{array}{c}7 \\
{[5-32]}\end{array}$ \\
\hline $\mathrm{hDam}_{\mathrm{r}}$ & 30 & 10 & 3 & $\mathrm{hDam}_{\mathrm{r}}$ & $\begin{array}{c}27 \\
{[18-34]}\end{array}$ & $\begin{array}{c}9 \\
{[7-16]}\end{array}$ & $\begin{array}{c}3 \\
{[3-4]}\end{array}$ \\
\hline
\end{tabular}

Fig. 4. Posterior frequency of inclusion (in \%) of the effect of the 6 studied reach characteristics (rows) on the 3 mortality rates (columns). Table A shows the results of the model for the 40 reaches. Table B summarizes the results of the leave-one-out deletion test, giving median [range] values for posterior frequency of inclusion. Gray scale is associated with the posterior frequency of inclusion. 

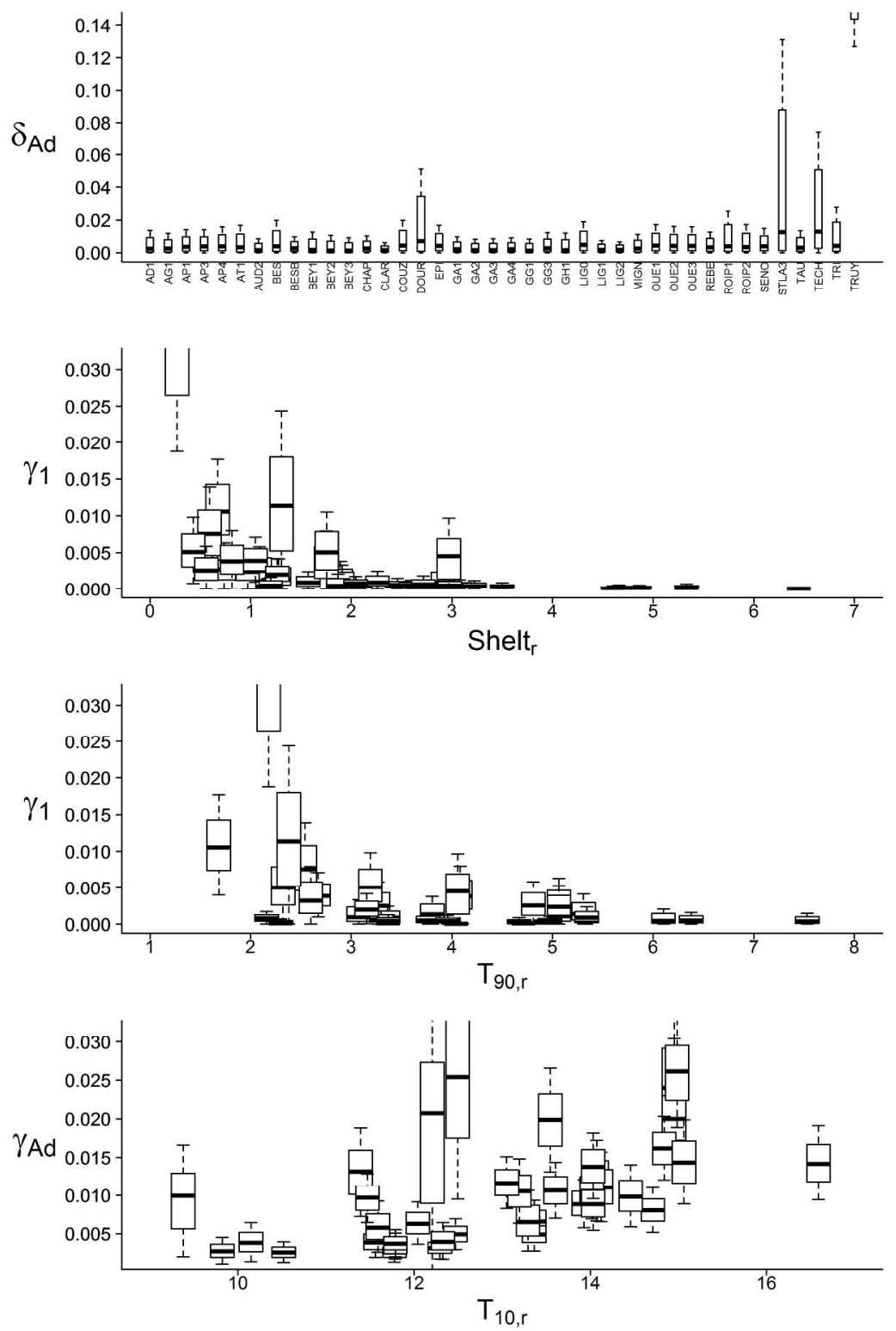

Fig. 5. Marginal posterior distributions of density-independent $\left(\delta_{\mathrm{Ad}}\right)$ and density-dependent $\left(\mathrm{Y}_{1}\right.$ and $\left.\mathrm{Y}_{\mathrm{Ad}}\right)$ mortality rates modeled by a hierarchical structure for the 40 reaches. The 1 st row shows the distribution of $\delta_{A d}$, which could not be explained by reach characteristics. The 2 nd to 5 th rows show change in densitydependent mortality distribution $\left(\mathrm{Y}_{1}\right.$ and $\left.\mathrm{Y}_{\mathrm{Ad}}\right)$ with shelter availability and inter-annual mean of percentile of water temperatures ( $T_{10}$ and $\left.T_{90}\right)$ as covariates.

$239 \times 359 \mathrm{~mm}(300 \times 300 \mathrm{DPI})$ 

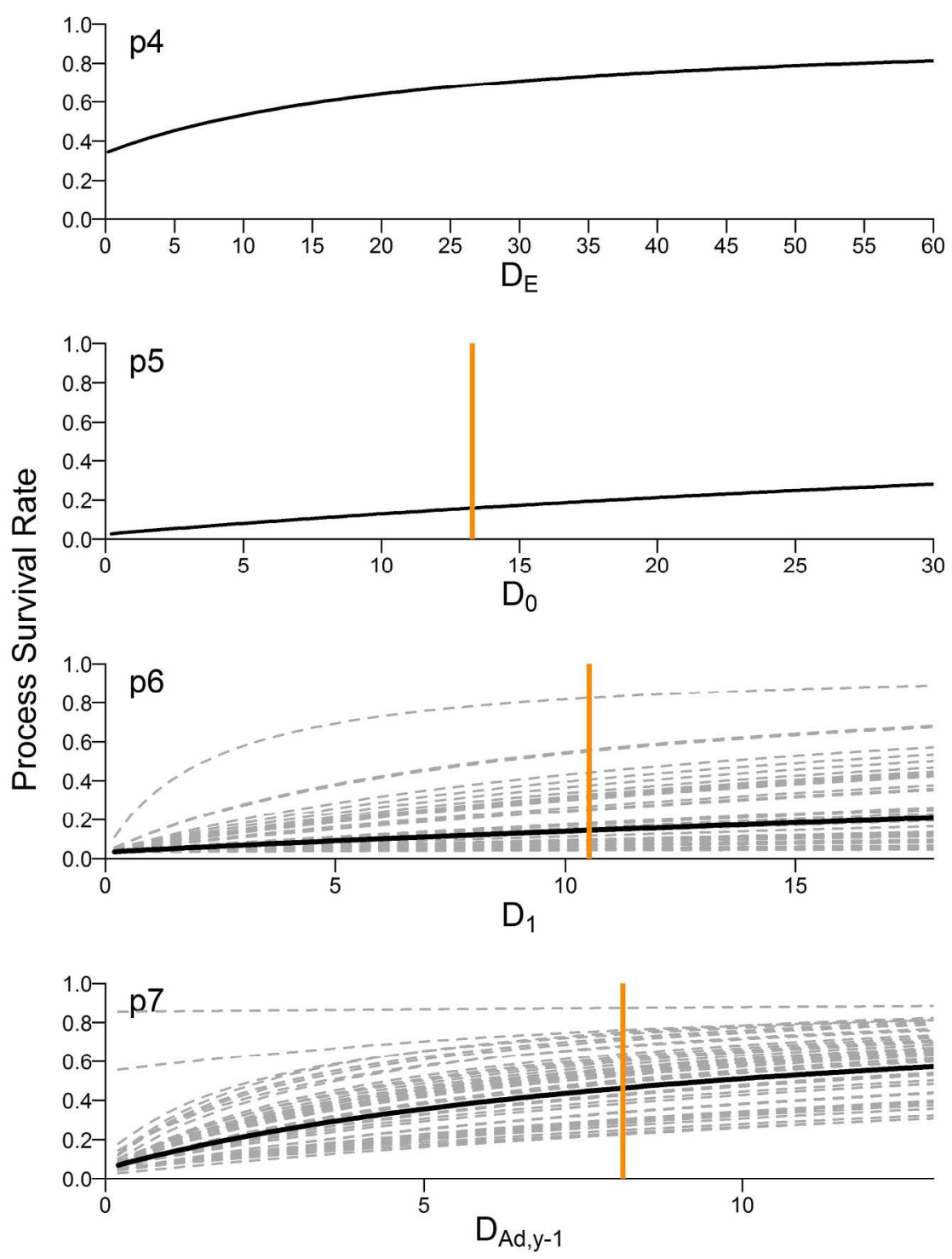

Fig. 6. Total mortality for the processes describing natural mortality between successive age-stages ( $p 4, p 5$, p6 and p7) for total process duration (respectively, 2, 10,12 and 12 months). When inter-reach variation in at least one mortality rate $\left(\delta_{k}\right.$ or $\left.\gamma_{k}\right)$ was detected for age-stage $k$, fitted relations for the 40 reaches are presented (dashed gray lines) along with the mean expected relation (solid line). A vertical line is drawn at mean observed densities for $0+, 1+$ and adults (densities were never observed at emergence); upper limits of $\mathrm{x}$-axes correspond to the 90th percentile of observed densities. Mortality from egg to emergent fry is not represented here, as mortality rates were not fitted but taken from the literature.

$$
199 \times 266 \mathrm{~mm} \text { ( } 300 \times 300 \text { DPI) }
$$





Fig. 7. Time series of observed and predicted densities of $0+, 1+$ and adult brown trout in 2 reaches (Bes and Senouire; columns). Points represent observed densities, associated with observation uncertainty (vertical lines). The black line shows the mean estimate of each year's predicted density. The shaded areas show the $50 \%$ and $95 \%$ confidence intervals for the predicted densities, when process error is considered.

$179 \times 129 \mathrm{~mm}(300 \times 300$ DPI $)$ 


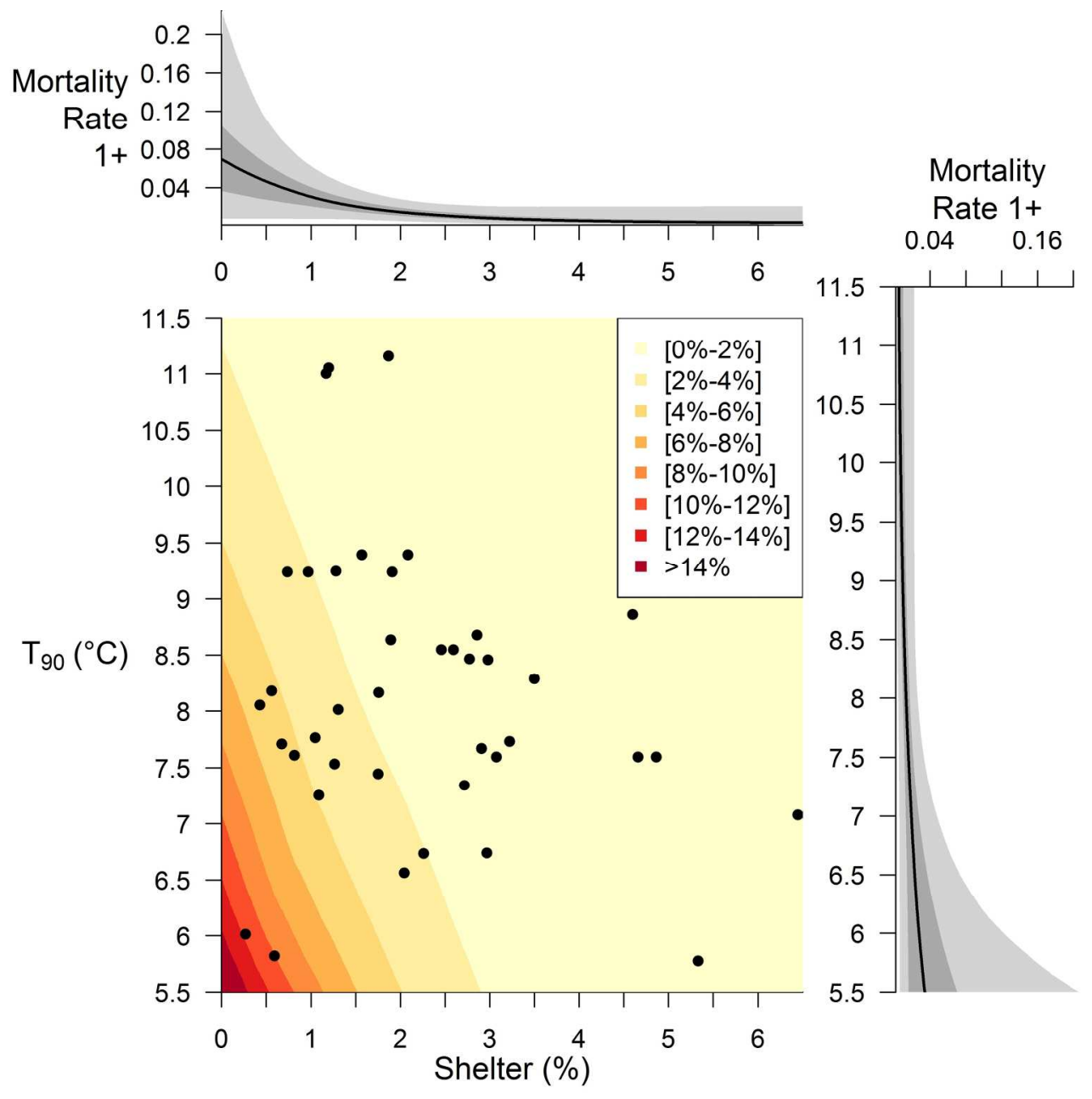

Fig. 8. Prediction of monthly mortality in $1+$ depending on shelter availability (x-axis) and inter-annual mean of a percentile of water temperatures $\left(\mathrm{T}_{90}\right)$ ( $\mathrm{y}$-axis). Black dots show the characteristics of reaches considered in this paper. Marginal relations are shown in upper and right sub-panels (shaded areas show $50 \%$ and $95 \%$ confidence intervals). Monthly mortality was computed by considering both densityindependent and density-dependent mortality and for mean initial densities (10.5 ind.100 $\mathrm{m}^{-2}$ for $1+$ and 8.1 ind $100 \mathrm{~m}^{-2}$ for adults).

$199 \times 199 \mathrm{~mm}(300 \times 300 \mathrm{DPI})$ 
1

3 Change in $D_{k}$ (density of age-stage $k$ ) was modeled by 1-month time steps. Mortality processes were

\section{Appendix A: Detailed modeling of the life-cycle}

4 described by the alternative formulation of the Beverton and Holt (1957) relationship.

5

6 7

(A1.2)

$$
\frac{1}{N_{m}} \cdot \frac{d N_{m}}{d m}=-\delta_{m}-\gamma_{m} \cdot D_{m}=-\delta_{m}-\frac{\gamma_{m}}{S} \cdot N_{m}
$$

Simple algebra on eq. (A1.1) leads to:

Assuming $\delta_{m}$ and $\gamma_{m}$ to be constant during the considered period, (A1.2) can be integrated from $m_{0}$ to $m_{1}\left(m_{1}=m_{0}+\Delta m\right)$ :

$$
\leftrightarrow \frac{d N_{m}}{N_{m}+\frac{\gamma m}{S . \delta_{m}} \cdot N_{m}^{2}}=-\delta_{m} \cdot d m
$$

$$
\leftrightarrow \frac{d N_{m}}{N_{m}}-\frac{d N_{m}}{\frac{\delta_{m} \cdot S}{\gamma_{m}}+N_{m}}=-\delta_{m} \cdot d m \text { (by the method of partial fractions) }
$$

$$
\begin{aligned}
& \int_{N=N_{m_{0}}}^{N=N_{m_{1}}} \frac{d N_{m}}{N_{m}}-\int_{N=N_{m_{0}}}^{N=N_{m_{1}}} \frac{d N_{m}}{\frac{\delta . S}{\gamma}+N_{m}}=-\int_{m=m_{0}}^{m=m_{1}} \delta . d m \\
& \leftrightarrow \ln \left(N_{m_{1}}\right)-\ln \left(N_{m_{0}}\right)-\left[\ln \left(\frac{\delta \cdot S}{\gamma}+N_{m_{1}}\right)-\ln \left(\frac{\delta \cdot S}{\gamma}+N_{m_{0}}\right)\right]=-\delta \cdot \Delta m \quad\left(a s \frac{\delta \cdot s}{\gamma}>0\right) \\
& \leftrightarrow \frac{N_{m_{1}}}{\frac{\delta . S}{\gamma}+N_{m_{1}}}=\frac{N_{m_{0}}}{\frac{\delta . S}{\gamma}+N_{m_{0}}} \cdot e^{-\delta . \Delta m} \\
& \leftrightarrow \frac{1}{N_{m_{1}}}=\frac{\gamma}{\delta . S}\left[\frac{\frac{\delta . S}{\gamma}+N_{m_{0}} \cdot\left(1-e^{-\delta . \Delta m}\right)}{N_{m_{0}} \cdot e^{-\delta \Delta m}}\right] \\
& \leftrightarrow N_{m_{1}}=\frac{N_{m_{0}}}{e^{\delta . \Delta m_{+}}+\frac{\gamma}{\delta . S} \cdot\left(e^{\delta . \Delta m_{-}}\right) \cdot N_{m_{0}}}
\end{aligned}
$$




$$
\leftrightarrow D_{m_{1}}=\frac{D_{m_{0}}}{e^{\delta . \Delta m_{+}} \frac{\gamma}{\delta}\left(e^{\left.\delta . \Delta m_{-1}\right) \cdot D_{m_{0}}}\right.}
$$

This relation (A1.3) hereafter denoted $D_{m_{1}}=B H\left(D_{m_{0}}, \delta, \gamma, \Delta m\right)$ is an alternative formulation of the

$$
\left\{\begin{array}{c}
N_{\Delta m}=\frac{\alpha \cdot N_{m_{0}}}{1+\alpha \cdot \beta \cdot N_{m_{0}}} \\
\alpha=e^{-\delta . \Delta m} \\
\beta=\frac{1}{\frac{\gamma}{\delta}\left(e^{\left.\delta . \Delta m_{-}\right)}\right.}
\end{array}\right.
$$

The model assumed constant mortality throughout a given age-stage $k$. Equation (A1.3) can relate densities of successive age-stages by considering the duration of the whole age-stage $\Delta m_{k}$ :

$$
D_{k+1}=B H\left(D_{k}, \delta_{k}, \gamma_{k}, \Delta m_{k}\right)
$$

It could also be used to express intermediate densities within a given age-stage $k$ (from $m_{0}$ to $m_{0}+$ $\Delta m):$

$$
D_{k, m_{0}+\Delta m}=B H\left(D_{k, m_{0}}, \delta_{k}, \gamma_{k}, \Delta m\right)
$$

We detail here the equations describing all steps of the brown trout life-cycle presented in (Fig. 2). These processes are associated with process errors taking account of unpredictable between-year variations around the expected process, as presented in the Methods section. For the sake of clarity, we did not index densities with the year $y$ and the reach $r$ considered $\left(D_{k}\right.$ being a simplification of $\left.D_{k, y, r}\right)$. Full indexing appears on Fig. 3.

\section{Spawning (p1)}

Density of spawning adults $D_{A d_{S p w}}$ in December (Elliott 1994) was multiplied by the brown trout sex- 
(Eq. A2.1)

$$
D_{E g g}=D_{A d_{S p w}} \varphi \cdot \psi \cdot K g_{A d, r}
$$

As we did not have local information on spawning processes for all reaches, previous studies on French trout populations were used to obtain global estimates for $\varphi$ and $\psi$. Their prior distributions were informative and centered on estimates found in the literature for the 3 parameters (Table 2). $\mathrm{Kg}_{\mathrm{Ad}, \mathrm{r}}$ was given in all reaches $r$ by field measurements (inter-annual median of measured weights).

\section{Under-gravel egg mortality (p2)}

We then assumed that no density-dependent mortality occurred during incubation and that emergence started in March (Gouraud et al. 2014). Initial densities of emergent fry $D_{\mathrm{E}_{\mathrm{i}}}$ were then modeled assuming only density-independent mortality $\delta_{\text {Egg }}$ operating on $\mathrm{D}_{\mathrm{Egg}}$ for 3 months.

(Eq. A2.2)

$$
D_{E_{i}}=B H\left(D_{E g g}, \delta_{E g g}, \gamma_{E g g}=0, \Delta m_{E g g}=3\right)
$$

Again, we did not have local information on monthly under-gravel mortality for all reaches, and we used a global informative prior for $\delta_{E g g}$ (Table 2), consistent with the observed survival rate of $90 \%$ for the whole period (Bardonnet and Prévost 1994).

\section{Abiotic mortality during emergence: flow velocity (p3)}

Emergence lasts up to 2 months (Elliott 1994), grouping together emergence in itself and early postemergence, which are both sensitive. During emergence, fry mortality occurs when flow velocity becomes too high (Heggenes and Traaen 1988; Armstrong et al. 2003). The influence of flow velocity was then modeled as an excess-mortality rate $\mu$, operating when $V_{10, E}$ (flow velocity for more than $10 \%$ of the time during emergence) was higher than a threshold $Z\left(\right.$ in $\left.\mathrm{m} \cdot \mathrm{s}^{-1}\right)$ :

$$
\text { (Eq. A2.3) } \quad \begin{cases}D_{E_{v}}=D_{E_{i}} & \text { if } V_{10, r, E}<Z \\ D_{E_{v}}=D_{E_{i}}(1-\mu) & \text { if } V_{10, r, E} \geq Z\end{cases}
$$

As flow velocity has the same implications everywhere, we assumed the process was operating similarly in all reaches: parameters $\mu$ and $\mathrm{Z}$ were therefore estimated globally.

Prior distributions for these parameters and all the following were weakly informative (Table 3).

\section{Mortality process during emergence (p4)}


61 Emergence is also characterized by high mortality while the young trout establish feeding territories

(Elliott 1994). We modeled natural fry mortality on specific mortality rates for these 2 months:

(Eq. A2.4)

$$
D_{0}=B H\left(D_{E_{v}}, \delta_{E}, \gamma_{E}, \Delta m_{E}=2\right)
$$

Available data (summer samplings) did not allow precise estimation of inter-reach variability in mortality during emergence. To ensure the convergence of the model, we had to estimate $\delta_{E}$ and $\gamma_{E}$ globally. Inter-year variations in emergence mortality (mostly linked to abiotic conditions) are known to be high (e.g., Hayes et al. 2010; Lobón-Cerviá et al. 2012). We therefore assumed, for this first step of modeling, that inter-reach variations were comparatively negligible.

\section{Mortality process during the end of the first year (Age-stage 0; p5)}

After this critical period, we assumed constant monthly mortality $\left(\delta_{0}\right.$ and $\left.\gamma_{0}\right)$ during the last 10 months of the first year of life, (age-stage 0 in Fig. 2). We modeled density for an intermediate state of age-stage $0, D_{O_{S p l}}$, at the month of sampling ( $\Delta m_{S p l}$ months after the beginning of the age-stage). This intermediate state was used to compute the likelihood of the model.

(Eq. A2.5)

$$
\left\{\begin{array}{c}
D_{O_{S p l}}=B H\left(D_{0}, \delta_{0}, \gamma_{0}, \Delta m=\Delta m_{S p l}\right) \\
D_{1}=B H\left(D_{O_{S p l}}, \delta_{0}, \gamma_{0}, \Delta m=12-\Delta m_{S p l}\right)
\end{array}\right.
$$

Inter-reach variation in mortality during age-stage 0 were not identified by our preliminary analyses (Appendix B). Those parameters were therefore estimated globally.

\section{Mortality process during the second year of life (Age-stage 1; p6)}

Trout from age-stage 1 surviving the $2^{\text {nd }}$ year of life become $2+$ trout (age-stage 2 being a subset of the adult age-stage):

(Eq. A2.6)

$$
\left\{\begin{array}{c}
D_{1_{S p l}}=B H\left(D_{1}, \delta_{1}, \gamma_{1, \mathrm{r}}, \Delta m=\Delta m_{S p l}\right) \\
D_{2}=B H\left(D_{1_{S p l}}, \delta_{1}, \gamma_{1, r}, \Delta m=12-\Delta m_{S p l}\right)
\end{array}\right.
$$

Preliminary analyses (Appendix B) revealed inter-reach variations in density-dependent mortality $\gamma_{1}$ but not density-independent mortality $\delta_{1}$. Thus, a hierarchical setting was used for $\gamma_{1}$ while $\delta_{1}$ was estimated globally. 
84

Adult mortality (p7)

The adult age-stage combined fish of several ages ( $2+$ and older).

(Eq. A2.7)

$$
\left\{\begin{array}{c}
D_{A d}=D_{2}+D_{>2} \\
\mathrm{D}_{A d_{S p l}}=B H\left(D_{A d}, \delta_{A d, r}, \gamma_{A d, r}, \Delta m=\Delta m_{S p l}\right) \\
D_{>2}=B H\left(\mathrm{D}_{A d_{S p l}}, \delta_{A d, r}, \gamma_{A d, r}, \Delta m=12-\Delta m_{S p l}\right)
\end{array}\right.
$$

Preliminary analyses (Appendix B) revealed inter-reach variations in both density-dependent mortality $\gamma_{\mathrm{Ad}}$ and density-independent mortality $\delta_{\mathrm{Ad}}$. Thus, a hierarchical setting was used for these parameters.

\section{Spawning adults (p8)}

Finally, the density of spawning adults in December was related to the mortality of adults from sampling to spawning $\left(\Delta m_{S p w}\right.$ months after sampling):

(Eq. A2.8)

$$
D A d_{S p w}=B H\left(\mathrm{D}_{A d_{S p l}}, \delta_{A d}, \gamma_{A d}, \Delta m=\Delta m_{S p w}\right)
$$

\section{A3. Appendix A: References}

Armstrong, J. D., Kemp, P. S., Kennedy, G. J. A., Ladle, M., and Milner, N. J. 2003. Habitat requirements of Atlantic salmon and brown trout in rivers and streams. Fish. Res. 62(2): 143-170. doi:doi:10.1016/S0165-7836(02)00160-1.

Bardonnet, A., and Prévost, E. 1994. Survie sous gravier de la truite (Salmo trutta) dans un affluent du Scorff.

Beverton, R. J. H., and Holt, S. J. 1957. On the dynamics of exploited fish populations. London, UK, Chapman \& Hall.

Elliott, J. M. 1994. Quantitative ecology and the brown trout. Oxford GBR, Oxford University Press.

Gouraud, V., Baran, P., Bardonnet, A., Beaufrère, C., Capra, H., Caudron, A., Delacoste, M., Lescaux, J. M., Naura, M., Ovidio, M., Poulet, N., Tissot, L., Sebaston, C., and Baglinière, J.-L. 2014. Sur quelles connaissances se baser pour évaluer l'état de santé 
107

108

109

110

111

112

113

114

115

116

117

118

119

des populations de truite commune (Salmo trutta)? Hydroécologie Appliquée: 1-28. doi:10.1051/hydro/2014001.

Hayes, J. W., Olsen, D. A., and Hay, J. 2010. The influence of natural variation in discharge on juvenile brown trout population dynamics in a nursery tributary of the Motueka River, New Zealand. New Zeal. J. Mar. Fresh. 44(4): 247-269. doi:10.1080/00288330.2010.509905.

Heggenes, J., and Traaen, T. 1988. Downstream migration and critical water velocities in stream channels for fry of four salmonid species. J. Fish Biol. 32(5): 717-727. doi:10.1111/j.1095-8649.1988.tb05412.x.

Lobón-Cerviá, J., Budy, P., and Mortensen, E. 2012. Patterns of natural mortality in streamliving brown trout (Salmo trutta). Freshw. Biol. 57(3): 575-588. doi:10.1111/j.13652427.2011.02726.x. 